\title{
Bifidobacterium breve and Lactobacillus rhamnosus treatment is as effective as budesonide at reducing inflammation in a murine model for chronic asthma
}

Seil Sagar ${ }^{1,2^{*}}$, Mary E Morgan ${ }^{1}$, Si Chen ${ }^{1}$, Arjan P Vos², Johan Garssen ${ }^{1,2}$, Jeroen van Bergenhenegouwen², Louis Boon ${ }^{3}$, Niki A Georgiou², Aletta D Kraneveld ${ }^{1}$ and Gert Folkerts ${ }^{1}$

\begin{abstract}
Background: Asthma is estimated to affect as many as 300 million people worldwide and its incidence and prevalence are rapidly increasing throughout the world, especially in children and within developing countries. Recently, there has been a growing interest in the use of potentially beneficial bacteria for allergic diseases. This study is aimed at exploring the therapeutic effects of long-term treatment with two different beneficial bacterial strains (Bifidobacterium breve M-16 V and Lactobacillus rhamnosus NutRes1) and a glucocorticoid (budesonide), as a reference treatment, on inflammatory response in a murine model for chronic allergic asthma.

Methods: To mimic the chronic disease in asthmatic patients, we used the murine ovalbumin-induced asthma model combined with prolonged allergen exposure. Airway function; pulmonary airway inflammation; airway remodelling, mRNA expression of pattern recognition receptors, Th-specific cytokines and transcription factors in lung tissue; mast cell degranulation; in vitro T cell activation; and expression of Foxp3 in blood Th cells were examined.
\end{abstract}

Results: Lactobacillus rhamnosus reduced lung resistance to a similar extent as budesonide treatment in chronically asthmatic mice. Pulmonary airway inflammation, mast cell degranulation, $T$ cell activation and airway remodelling were suppressed by all treatments. Beneficial bacteria and budesonide differentially modulated the expression of toll-like receptors (TLRs), nod-like receptors (NLRs), cytokines and T cell transcription factors. Bifidobacterium breve induced regulatory T cell responses in the airways by increasing $1 / 10$ and Foxp3 transcription in lung tissue as well as systemic by augmenting the mean fluorescence intensity of Foxp3 in blood CD4+ T cells.

Conclusion: These findings show that Bifidobacterium breve M-16 V and Lactobacillus rhamnosus NutRes 1 have strong anti-inflammatory properties that are comparable to budesonide and therefore may be beneficial in the treatment of chronic asthma.

Keywords: Allergic asthma, Beneficial bacteria, Glucocorticoids, Regulatory T cell

\footnotetext{
* Correspondence: seilsag@gmail.com

'Division of Pharmacology, Utrecht Institute for Pharmaceutical Sciences, Faculty of Science, Utrecht University, PO box 80082, 3508 TB Utrecht, The Netherlands

${ }^{2}$ Danone Research, Centre for Specialised Nutrition, Wageningen, The Netherlands

Full list of author information is available at the end of the article
} 


\section{Background}

Allergic asthma is a T helper type-2 (Th2) cell-mediated chronic inflammatory disorder of the airways with rapidly increasing incidence and prevalence throughout the world, especially in children and within developing countries [1]. It is characterised by airway inflammation and hyper-responsiveness (AHR) [2]. Structural changes in the airway walls of asthmatic patients, referred to as "airway remodelling", are caused by persistent inflammation and subsequent inadequate repair of damaged airway epithelium [3-5].

Various cells are involved in cellular airway inflammation and subsequent airway remodelling, such as eosinophils, neutrophils, $\mathrm{T}$ lymphocytes and mast cells [4]. Infiltration of mast cells into the airway smooth muscle cell layer of allergic asthmatics is a key feature of asthma and is thought to be associated with AHR [6,7]. Upon mast cell degranulation various inflammatory mediators, such as vasoactive amines, cytokines and proteases are released [8,9]. Mouse mast cell protease 1 (mMCP-1) was reported to enhance airway narrowing in mice through effects on the epithelium [10,11].

Glucocorticoids (GCs) are by far the most effective treatments for asthma [12]. Besides the undesirable side effects of long-term GC therapy, a significant number of asthmatics is steroid resistant and fails to respond to this therapy $[13,14]$. These limitations of GCs therapy highlight the need for novel therapeutics with long-term benefits, greater disease control and increased efficacy.

Changes in the microbiota were reported to contribute to the development of allergies and asthma $[15,16]$. The potential role of beneficial bacteria, such as probiotics, as modulators of the intestinal microbiota and mucosal immune responses has been extensively investigated and discussed in the last few years [17-19]. Probiotics are "live microorganisms which, when consumed in adequate amounts, confer a health benefit on the host" [20,21]. Bifidobacteria and Lactobacilli, which are a part of the gut microbiota, were effective in suppressing both allergic and autoimmune responses, reducing allergic symptoms and inhibiting allergic airway response in murine models of acute airway inflammation [22-26].

Because they contain toll-like receptor (TLR) ligands, it is believed that beneficial bacteria can modulate TLRdriven responses and also skew the immune balance towards a Th1-associated response [27]. The TLRs and nod-like receptors (NLRs) are key pattern recognition receptor (PRR) families in the innate immune response. In the human airways, the RRRs are expressed in or on dendritic cells (DCs), epithelial cells, eosinophils, macrophages and mast cells $[28,29]$. Following TLR and NLR activation in the lung, various chemokines and cytokines are produced by eosinophils and mast cells that attract activated B-lymphocytes and Th lymphocytes to the lung to orchestrate the inflammation in the airways [30].

The function and expression of PRRs were linked to susceptibility towards allergic asthma [31,32]. Functional genetic variations in TLR1, TLR10 and TLR6 genes affecting gene and protein expression were associated with increased mRNA expression of these TLRs and protected against atopic asthma in humans [32]. Genetic variations in TLR2, NOD1 and NOD2 genes that led to either decreased mRNA expression and affected microbial recognition, respectively, were positively associated with disease susceptibility and pathogenesis [25,33-36]. Cord blood CD34 (+) cells from high-atopic-risk infants have been reported to have low TLR2, TLR4, and TLR9 expression and the latter was demonstrated to exert protective immunomodulatory effects on asthma [37-39]. Tlr3 contributes to asthma exacerbations in mice [40] and a study in a murine macrophage cell line suggested a pro-inflammatory role of Tlr4 and 5 in the disease [41].

In asthma, over 50 cytokines have now been identified to affect disease outcome. Strong pro-inflammatory and Th2-associated cytokines; including interleukin-1 $\beta$

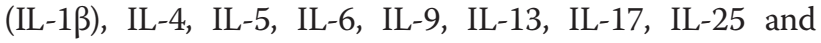
tumor necrosis factor $\alpha$ (TNF- $\alpha)$ were reported to enhance asthma [30]. On the other hand, Th1-associated cytokines; IL-12, IL-18 and interferon- $\gamma$ (IFN $\gamma$ ) were reported to reduce the symptoms of the disease [30]. Additionally, subjects with asthma were reported to have reduced levels of the anti-inflammatory cytokine IL-10 in the sputum [42]. Moreover, Th1/Th2 imbalances as well as disturbed $\mathrm{T}$ helper type-17(Th17)/Treg balances were reported in asthmatic patients [43]. Imbalances in Th responses can also be detected using Th-specific transcription factors: T-bet for Th1 cells, GATA-3 for Th2 cells, retinoic acid orphan receptor-yt (ROR $\gamma \mathrm{t}$ ) for Th17 cells and forkhead box P3 (Foxp3) for Tregs [44]. Alterations in the expression and/or function of Th-specific transcription factors were associated with asthma pathogenesis $[45,46]$.

This study aimed to explore the therapeutic effects of long-term administration of Bifidobacterium breve M-16 V and Lactobacillus rhamnosus NutRes1 on chronic airway inflammation and remodelling in mice. A glucocorticoid was used as a reference treatment. Findings from this study will contribute to a better understanding of the immunomodulatory and therapeutic effects of beneficial bacteria in chronic allergic asthma.

\section{Methods}

\section{Animals}

Male BALB/c mice (6-8 weeks; Charles River Laboratories, France) were acclimated to their new environment for at least 1 week before the start of the experiment. Mice were housed under standard conditions and had free access to food and water. All in vivo experiments were approved by 
and were in accordance with the guidelines of the local Dutch Committee of Animal Experimentation.

\section{Chronic asthma model OVA sensitisation}

Sensitisations were performed on days 0 and 12. Mice were sensitised to OVA (chicken egg albumin, grade V, Sigma, St. Louis, MO, USA) by intraperitoneal injections of $0.1 \mathrm{~mL}$ alum-precipitated antigen, comprising $10 \mu \mathrm{g}$ OVA absorbed into $2.25 \mathrm{mg}$ alum (AlumImject; Pierce, Rockford, IL, USA). Control animals received $0.1 \mathrm{~mL}$ saline only $(\mathrm{NaCl} 0.9 \%$; B. Braun Medical B.V., Oss, The Netherlands) (Figure 1).

\section{OVA challenge}

A chronic model of asthma was established according to a modification of a model of prolonged allergen-induced airway inflammation described in [2]. Mice were exposed daily to 5\% OVA aerosol in saline or saline only using a Pari LC Star nebuliser (PARI GmbH, Starnberg, Germany) in an aerosol cabin for 20 min between days 17 and 23. Control animals were exposed to nebulised saline aerosol only. From day 24 until day 55, the frequency of challenge was reduced to three times a week and mice were exposed to aerosolised OVA (5\%) or saline only for $20 \mathrm{~min}$ (Figure 1).

\section{Beneficial bacteria treatment}

Bifidobacterium breve M-16 V (B. breve, Morinaga Milk Industry, Tokyo, Japan) and Lactobacillus rhamnosus NutRes1 (L. rhamnosus, Danone Research, Wageningen, the Netherlands) were grown in MRS (Oxoid, Basingstoke, UK), supplemented with $0.5 \mathrm{~g} / \mathrm{L} \mathrm{L}$-cysteine for Bifidobacteria, at pH 6.5 and under anaerobic conditions. Bacteria were harvested in the early stationary phase, washed with phosphate buffered saline (PBS, Lonza Leusden, The Netherlands) and stored with glycerol 20\% (w/v), in aliquots at $-80^{\circ} \mathrm{C}$. Cell counts were determined by plating serial dilutions and fluorescent microscopy by staining with DAPI. The bacteria were resuspended in PBS prior to use.

After development of airway inflammation, mice received $10^{9}$ colony forming units (CFUs) of B. breve or $1.1 \times 10^{9} \mathrm{CFUs}$ of $L$. rhamnosus per animal per day. Bacterial strains were suspended in $0.2 \mathrm{~mL}$ of PBS and given by oral gavage, $1 \mathrm{~h}$ prior to challenge, three times a week from day 22 until day 55 (Figure 1).

\section{Budesonide treatment}

As a reference treatment, mice received $0.5 \mu \mathrm{g} / \mathrm{g}$ of mouse/day of budesonide (Sigma) in PBS. Budesonide was administered to mice by oropharyngeal aspiration after induction of light isoflurane anesthesia as described previously in [47], $1 \mathrm{~h}$ prior challenge, three times a week from day 22 until day 55 . Control animals received $50 \mathrm{uL}$ of PBS by the same administration route. Mice were rendered asthmatic following the schema presented in Figure 1.

\section{Airway response to methacholine}

On day 56, $24 \mathrm{~h}$ after the last OVA aerosol challenge, the airway response to increasing doses of methacholine was analysed after insertion of a cannula in the trachea. Lung resistance in anesthetized, mechanically ventilated mice was measured directly using whole-body plethysmography (Emka technologies, Paris, France). Mice were exposed to saline $(0 \mathrm{mg} / \mathrm{mL}$ methacholine) and increasing doses (0.38 to $25 \mathrm{mg} / \mathrm{mL}$ ) of aerosolised methacholine (Sigma).

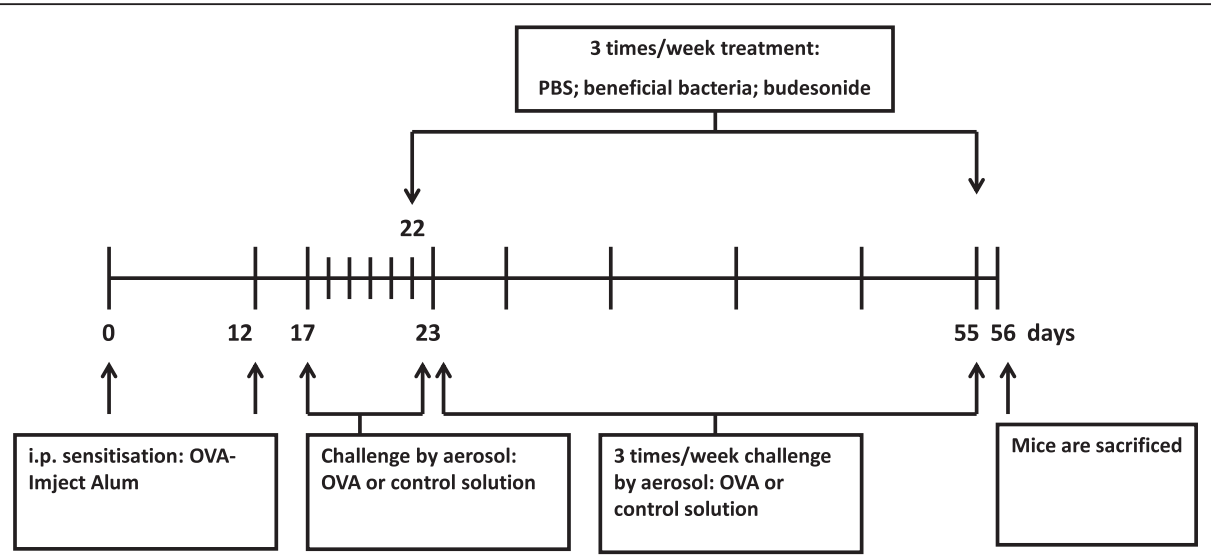

Figure 1 Time schedule of the chronic asthma mouse model. Male BALB/C mice were sensitised intraperitoneally to OVA-ImjectAlum on days 0 and 12 and mice were challenged from day 17 until day 23 daily with aerosolised OVA or saline. From day 22 until day 55, mice were treated 3 times a week with either PBS or budesonide by oropharyngeal aspiration or beneficial bacteria (B. breve or L. rhamnosus) by oral gavage. $1 \mathrm{~h}$ after treatment, from day 24 until day 55, mice were challenged 3 times/week with aerosolised OVA or saline. Mice were sacrificed on day 56 after pulmonary function measurement. 


\section{Bronchoalveolar lavage}

After sacrifice, on day 56, lungs were first lavaged through a tracheal cannula with $1 \mathrm{~mL}$ saline containing protease inhibitor cocktail (Complete Mini, Roche Diagnostics, Mannheim, Germany), pre-warmed at $37^{\circ} \mathrm{C}$. This was followed by 3 additional lavages with $1 \mathrm{~mL}$ saline only. Cytospin cell preparations were made by cytospinning the cells onto glass for 5 min $\left(400 g, 4^{\circ} \mathrm{C}\right)$ and cytospins were stained by DiffQuick (Merz \& Dade AG, Düdingen, Switzerland). Numbers of eosinophils, macrophages, neutrophils and lymphocytes were scored by light microscopy.

\section{RNA isolation and quantitative real-time PCR}

After mice were sacrificed on day 56, the lungs were dissected and mRNA was isolated from whole lung tissue. Messenger RNA isolation ( $\mathrm{n}=6$ mice per group) was carried out according to the Qiagen RNeasy Mini Kit protocol (Qiagen Benelux B.V., Venlo, The Netherlands). Reverse transcriptase PCR was performed using an iScript ${ }^{\text {tw }} \mathrm{cDNA}$ Synthesis Kit (Bio-Rad Laboratories, Hercules, CA, USA). The reactions were performed in a PTC-100TM Programmable Thermal Controller (M. J. Research Inc., Waltham, Massachusetts, USA) according to manufacturer's protocol.

cDNA was amplified using iQ SYBR Green supermix in a 96-well PCR plate and run in a CFX96 Real-Time PCR Detection System (Bio-Rad). Primers for TLRs, NLRs, ribosomal protein S13 (RPS13, reference gene) and T cell transcription factors were purchased by Isogen (Isogen Life Science, De Meern, The Netherlands). The sequences are listed in Additional file 1: Table S1. For mouse T cell cytokines, $\mathrm{RT}^{2}$ qPCR Primer Assays (SABiosciences, Venlo, The Netherlands) were used. The protocol used for amplification was $94^{\circ} \mathrm{C}$ for $3 \mathrm{~min}, 94^{\circ} \mathrm{C}$ for $10 \mathrm{sec}$, specific melt temperature for $45 \mathrm{sec}$, followed by 39 cycles of $94^{\circ} \mathrm{C}$ for $10 \mathrm{sec}$ and $95^{\circ} \mathrm{C}$ for $10 \mathrm{sec}$.

Normalised gene expression $\left(\Delta \Delta \mathrm{C}_{\mathrm{T}}\right)$ was calculated using the built-in gene expression analysis module in CFX Manager $^{\mathrm{Tw}}$ software (CFX Manager ${ }^{\mathrm{Tw}}$ software version 1.6).

\section{Foxp3 staining and flow cytometry}

On days 0 and 56, blood samples were collected from mice by cardiac puncture in tubes containing lithium heparin to prevent coagulation. The blood was then washed in PBS and, after centrifugation; the pellet was subjected to red cell lysis using a buffer containing $\mathrm{NH}_{4} \mathrm{Cl}$ (MERCK, Darmstadt Germany), $\mathrm{KHCO}_{3}$ (Sigma), ethylenediaminetetraacetic acid (EDTA, MERCK) in demineralised water for $5 \mathrm{~min}$ on ice. After several washes with PBA (PBS containing $1 \%$ bovine serum albumin (BSA, Roche Diagnostics, Almere, The Netherlands) cells were resuspended in PBA and kept on ice until Foxp3 staining.
The expression of Foxp3 was measured using the Foxp3 Staining Buffer Set (eBioscience, San Diego, CA, USA) using the following protocol: cells were incubated in Fixation/Permeabilization buffer for $30 \mathrm{~min}$ on ice. Cells were then washed once with PBA followed by two washes with permeabilization buffer. After a 15 min preincubation in total mouse serum blocking reagent on ice, cells were washed once with permeabilization buffer and then stained with anti-CD4 (FITC, eBioscience), anti-CD25 (PE, eBioscience) and anti-Foxp3 (APC, eBioscience) for $30 \mathrm{~min}$ on ice. Cells were washed twice with permeabilization buffer and resuspended in PBA for flow cytometry analysis.

Tregs were defined as CD4 + Foxp3 + CD25hi T cells. The stained cells were analysed on a FACSCanto II flow cytometer (BD Biosciences, USA). Data analysis was performed using BD FACSDiva ${ }^{\text {tm }}$ software (BD Biosciences). The gating strategy is illustrated in Additional file 2: Figure S1.

\section{Measurement of mouse mast cell protease 1 levels in serum}

To assess mast cell activation, after mice were sacrificed on day 56, blood samples were collected from mice by cardiac puncture. The blood was coagulated for $1 \mathrm{~h}$ at room temperature and subsequently centrifuged for $5 \mathrm{~min}$ at $17,500 \mathrm{~g}$. Serum samples were stored at $-80^{\circ} \mathrm{C}$ until further analysis. Mouse mast cell protease 1 (mMCP-1) protein expression levels in serum were determined by enzyme-linked immunosorbent assay (ELISA) using the Mouse MCPT-1 (mMCP-1) ELISA Ready-SET-Go! ${ }^{\circ}$ kit (eBioscience) according to manufacturer's protocol.

\section{Measurement of cytokine production by $T$ cells in thoracic lymph nodes after restimulation with anti-CD3 antibody in vitro}

In order to examine specific $\mathrm{T}$ cell responses, after mice were sacrificed on day 56, lung-draining lymph nodes were collected from the thorax and transferred to cold sterile PBS. Single cell suspensions of the thoracic lymph nodes (TLNs) were made using a $70 \mu \mathrm{m}$ nylon cell strainer (BD Biosciences) and rinsed with $15 \mathrm{~mL}$ of PBS. The cells were washed and resuspended in RPMI 1640 culture medium without L-glutamine and phenol red (Lonza) supplemented with $10 \%$ heat-inactivated fetal calf serum (FCS, Hyclone Laboratories, USA) and $0.1 \%$ penicillinstreptomycin solution (pen-strep, Sigma). The total number of cells was determined using a Beckman Z1 coulter Particle Counter (Beckman, USA). TLN cells $\left(4 \times 10^{6}\right.$ cells $/ \mathrm{mL}$ ) were cultured in a Greiner bio-one CellSTAR 96-well U-bottom plate (Greiner Bio-One B.V., Alphen a/d Rijn, The Netherlands) in medium with or without $\mathrm{O} / \mathrm{N}$ pre-coating of the wells with $50 \mu \mathrm{g} / \mathrm{mL}$ of anti-CD3 antibody (Bioceros BV, Utrecht, The Netherlands). The 
supernatant was harvested after 5 days of culture at $37^{\circ} \mathrm{C}$ in $5 \% \mathrm{CO} 2$ and stored at $-20^{\circ} \mathrm{C}$ until further analysis.

The levels of cytokines in the supernatant were measured by flow cytometry using a $\mathrm{BD}^{\mathrm{Tw}}$ Cytometric Bead Array (CBA) Mouse Th1/Th2/Th17 Cytokine kit (BD Biosciences) according to manufacturer's protocol on a FACSCanto II flow cytometer (BD Biosciences). Data analysis was performed using BD FCAP Array ${ }^{\text {ma }}$ v3.0.1 Software (BD Bisosciences).

\section{Histology and immunohistochemistry}

After mice were sacrificed on day 56, lungs were fixed with $10 \%$ formalin infusion through a tracheal cannula at a constant pressure of $25 \mathrm{~cm} \mathrm{H} \mathrm{H}_{2} \mathrm{O}$. The lungs were immersed in fixative for at least $24 \mathrm{~h}$, after which the left lung was embedded in paraffin. After paraffin embedding, $5 \mu \mathrm{m}$ sections were cut and de paraffin sections were first deparaffinised. Endogenous peroxidase activity was blocked with $0.3 \% \mathrm{H}_{2} \mathrm{O}_{2}$ (Merck) in methanol for $30 \mathrm{~min}$ at room temperature and rehydrated in a graded ethanol series to PBS and paraffin section were stained with hematoxylin/eosin (H\&E) for inflammation, periodic acidschiff (PAS) for goblet cells, Masson's trichrome for connective tissue, rabbit polyclonal anti- $\alpha$-smooth muscle actin antibody (Abcam, Cambridge, UK) for smooth muscle cells and rabbit polyclonal anti-Ki76 antibody (Abcam) for proliferating cells according to standard methods. Photomicrographs were taken with an Olympus BX50 microscope equipped with a Leica DFC 320 digital Camera.

Slides were reviewed in blinded fashion by two observers independently and slides were scored on the basis of the percentage of positive stained cells in the following way: - , no positive staining; $+/-$, less than $25 \%$ of cells stained positive;,+ 25 to $50 \%$ cells stained positive;,++ 50 to $75 \%$ cells stained positive.

\section{Statistical analysis}

Data analysis was performed using a 1-way analysis of variance (one-way ANOVA) with the Bonferroni's posthoc test. Linear regression analysis was used to calculate correlations. All statistical analyses were performed using GraphPad Prism software program (GraphPad Prism software version 5.03).

\section{Results}

L. rhamnosus and budesonide reduce the increased lung resistance in chronically asthmatic mice

To investigate the lung function in the chronic asthmatic mice after treatments, lung resistance was measured (Table 1). OVA-sensitised and challenged control mice (OVA/OVA-PBS) showed a significant increase in the basal lung resistance and lung resistance at all concentrations of methacholine as compared to the sensitised only control group (OVA/Sal-PBS). Treatment of sensitised and challenged mice with $L$. rhamnosus (OVA/OVAL. rhamnosus) resulted in a significant decrease in the basal lung resistance and lung resistance at $0,0.75$ and $1.56 \mathrm{mg} / \mathrm{mL}$ methacholine as compared to the OVA/ OVA-PBS group. Budesonide treatment significantly decreased the basal lung resistance and lung resistance at 0 , $0.38,0.75$ and $1.56 \mathrm{mg} / \mathrm{mL}$ methacholine in allergic mice (OVA/OVA-BUD) as compared to OVA/OVA-PBS mice. The basal lung resistance and lung resistance at all concentrations of methacholine remained unchanged in $B$. breve-treated, sensitised and challenged mice (OVAOVA-B. breve) as compared to the OVA/OVA-PBS group.

\section{B. breve and $L$. rhamnosus are as effective as budesonide in reducing pulmonary inflammation in chronically asthmatic mice}

To gauge the extent of inflammation in the asthmatic mice after treatments, bronchoalveolar lavage (BAL) fluid was examined for leukocyte accumulation (Figure 2). OVA/OVA-PBS mice showed a significant increase in the total inflammatory cell number $\left(155.25 \times 10^{4} \pm 12.58\right.$; $\mathrm{n}=6 ; \mathrm{p}<0.0001)$ in the BAL fluid, which was due to a relative increase in the number of macrophages, eosinophils and neutrophils as compared to OVA/Sal-PBS mice $\left(29.25 \times 10^{4} \pm 3.12 ; \mathrm{n}=6\right)$. All treatments significantly reduced the total number of inflammatory cells in the BAL fluid of OVA/OVA mice. Budesonide treatment significantly decreased the total inflammatory cell number $\left(83.70 \times 10^{4} \pm 13.66 ; \mathrm{n}=6 ; \mathrm{p}<0.0001\right)$ and relative number of eosinophils and neutrophils in OVA/OVA-BUD mice. B. breve treatment, however, further decreased the total inflammatory cell number $\left(73.50 \times 10^{4} \pm 6.42, \mathrm{n}=6\right.$; $\mathrm{p}<0.0001)$ and significantly decreased the relative number of eosinophils and neutrophils. L. rhamnosus treatment significantly decreased the total inflammatory cell number $\left(79.75 \times 10^{4} \pm 17.49 ; \mathrm{n}=6 ; \mathrm{p}<0.0001\right)$ and relative number of neutrophils.

\section{B. breve and L. rhamnosus modulate TLR and NLR mRNA expression in lung tissue of chronically asthmatic mice} As PRRs in the lung can modulate ongoing chronic inflammation during asthma, the mRNA expression of Tlr1-9 and Nod1-2 were measured (Figure 3). The mRNA expression of Tlr3 and Nod 1 was significantly decreased and Tlr 9 was also decreased $(\mathrm{p}>0.05)$ in OVA/OVA-PBS mice as compared to the OVA/Sal-PBS group (Figure 3A). After $B$. breve treatment, the OVA/OVA-B. breve mice showed a significant increase in $T l r 9$ expression compared to the OVA/OVA-PBS group. In non-asthmatic controls, Tlr1 and Tlr2 expression was significantly increased in the OVA-Sal-B. breve group as compared to OVA/Sal-PBS mice, yet, the expression of the other PRRs in non-asthmatic controls remained unchanged. B.breve treatment in 
Table 1 L. rhamnosus and budesonide treatment reduce the basal lung resistance in chronic asthmatic mice

\begin{tabular}{|c|c|c|c|c|c|c|c|c|c|c|c|c|c|c|c|c|c|c|}
\hline \multirow[t]{3}{*}{ Group } & \multicolumn{18}{|c|}{ Methacholine $(\mathrm{mg} / \mathrm{mL})$} \\
\hline & \multicolumn{2}{|l|}{ Basal } & \multicolumn{2}{|c|}{0 (saline) } & \multicolumn{2}{|l|}{0.38} & \multicolumn{2}{|l|}{0.75} & \multicolumn{2}{|l|}{1.56} & \multicolumn{2}{|l|}{3.13} & \multicolumn{2}{|l|}{6.25} & \multicolumn{2}{|l|}{12.5} & \multicolumn{2}{|l|}{25} \\
\hline & Mean & SEM & Mean & SEM & Mean & SEM & Mean & SEM & Mean & SEM & Mean & SEM & Mean & SEM & Mean & SEM & Mean & SEM \\
\hline OVA/Sal-PBS & 0.73 & 0.09 & 0.76 & 0.09 & 0.80 & 0.06 & 0.88 & 0.06 & 0.97 & 0.08 & 1.04 & 0.09 & 1.16 & 0.06 & 1.23 & 0.07 & 1.41 & 0.12 \\
\hline OVA/OVA-PBS & $1.81^{\#}$ & 0.31 & $1.79^{\#}$ & 0.22 & $1.76^{\#}$ & 0.19 & $1.85^{\#}$ & 0.20 & $1.86^{\#}$ & 0.21 & $1.82^{\#}$ & 0.19 & $1.73^{\#}$ & 0.15 & $1.96^{\#}$ & 0.18 & $2.01^{\#}$ & 0.21 \\
\hline OVA/Sal-B. breve & 0.61 & 0.09 & 0.76 & 0.15 & 0.93 & 0.21 & 0.96 & 0.17 & 0.97 & 0.13 & 1.00 & 0.07 & 1.12 & 0.09 & 1.17 & 0.09 & 1.16 & 0.06 \\
\hline OVA/OVA-B. breve & 1.74 & 0.58 & $1.66^{a}$ & 0.59 & 1.54 & 0.43 & 1.55 & 0.33 & 1.66 & 0.28 & 1.86 & 0.30 & 1.97 & 0.27 & 2.18 & 0.29 & 2.36 & 0.30 \\
\hline OVA/Sal-L. rhamnosus & 0.64 & 0.09 & $0.73^{\#}$ & 0.16 & 0.74 & 0.09 & 0.81 & 0.11 & 0.83 & 0.08 & 0.93 & 0.08 & 1.02 & 0.10 & 1.05 & 0.08 & 1.20 & 0.12 \\
\hline OVA/OVA-L. & $1.05^{\alpha}$ & 0.18 & $1.15^{\mathrm{a}}$ & 0.14 & 1.13 & 0.13 & $1.18^{\mathrm{a}}$ & 0.13 & $1.30^{\alpha}$ & 0.12 & 1.48 & 0.13 & 1.55 & 0.14 & 1.69 & 0.16 & 1.80 & 0.16 \\
\hline OVA/Sal-BUD & 0.55 & 0.02 & $0.56^{\#}$ & 0.02 & 0.63 & 0.04 & 0.71 & 0.07 & 0.79 & 0.09 & 0.85 & 0.10 & 0.96 & 0.09 & 1.08 & 0.12 & 1.17 & 0.11 \\
\hline OVA/OVA-BUD & $0.85^{\mathrm{x}}$ & 0.12 & $0.88^{\alpha}$ & 0.09 & $1.01^{\mathrm{a}}$ & 0.09 & $1.10^{\mathrm{a}}$ & 0.09 & $1.23^{a}$ & 0.13 & 1.38 & 0.13 & 1.57 & 0.15 & 1.73 & 0.10 & 1.80 & 0.16 \\
\hline
\end{tabular}

Airway response to saline and increasing doses of methacholine measured $24 \mathrm{~h}$ after the last OVA or saline challenge as expressed by lung resistance (LR). Basal airway response is also shown. Mice in all groups were sensitised to OVA. OVA/Sal mice were challenged with saline; OVA/OVA mice were challenged with OVA. Mice were treated with PBS (OVA/Sal-PBS; OVA/OVA-PBS), B. breve (OVA/Sal-B. breve; OVA/OVA-B. breve), L. rhamnosus (OVA/Sal-L. rhamnosus; OVA/OVA-L. rhamnosus) or budesonide (OVA/Sal-budesonide; OVA/OVA-budesonide). Results are shown as mean \pm SEM, $n=6$ mice/group. Statistical significance of differences was tested using post hoc Bonferroni's multiple comparison test after one-way ANOVA. \#Statistically significant difference ( $p<0.05$ ) compared to OVA/Sal-PBS mice. ${ }^{a}$ Statistically significant difference $(p<0.05)$ compared to OVA/OVA-PBS mice. BUD = budesonide.

asthmatic mice significantly increased $\operatorname{Tl} 9$ expression and decreased Tlr2, Tlr3, Tlr5 and Nod1 expression in the OVA/OVA-B. breve group as compared to the OVASal-B. breve group (Figure 3B). Mice in the OVA/OVAbudesonide group showed significant increases in the expression of Tlr3 and Nod1 and Tlr9 expression was higher $(\mathrm{p}>0.05)$ as compared to the OVA/OVA-PBS group. The expression of Tlr3 and Tlr5 was significantly decreased in OVA/Sal-budesonide mice as compared to the OVA/Sal-PBS group (Figure 3C). The OVA/OVAL. rhamnosus group showed a significant decrease in Tlr4, an increase in Tlr3 and higher Tlr9 expression compared to OVA/OVA-PBS mice. The mRNA expression of Tlr1, Tlr2, Tlr4, Tlr6, Nod1 and Nod2 was significantly decreased in OVA/OVA- L. rhamnosus mice as compared to the OVA/Sal-L. rhamnosus group (Figure 3D).

\section{Beneficial bacteria and budesonide treatment modulate cytokine mRNA expression in lung tissue of chronically asthmatic mice}

To determine the extent of inflammation and the Th response in the lung, the mRNA expression of various cytokines was measured (Figure 4). The mRNA expression of $I l 1 \beta$ and Il6 was significantly increased and Il13 and Ill expression was also increased $(\mathrm{p}>0.05)$ in OVA/OVAPBS mice as compared to the OVA/Sal-PBS group (Figure 4A). The OVA/OVA-B. breve group showed a significant increase in $I l 4$ and $I l 10$ expression as compared to the OVA/OVA-PBS group. Expression of Il1 $\beta$ and Il6 was significantly increased in OVA/Sal-B. breve mice as compared to the OVA/Sal-PBS group. The mRNA expression of these two cytokines was significantly decreased in OVA/OVA- $B$. breve mice as compared to the OVA/Sal$B$. breve group (Figure 4B). The OVA/OVA-budesonide group showed a significant decrease in the expression of Tnf $\alpha$ as compared to OVA/OVA-PBS mice. Expression of Ill3 was significantly increased and $T g f \beta$ expression was significantly decreased in OVA/Sal-budesonide mice as compared to the OVA/Sal-PBS group. The mRNA expression of $I l 23$ and $T g f \beta$ was significantly increased in OVA/ OVA-budesonide mice as compared to the OVA/Salbudesonide group (Figure $4 \mathrm{C}$ ). L. rhamnosus treatment significantly decreased the expression of Il6 in OVA/ OVA-L. rhamnosus mice as compared to the OVA/OVAPBS group. The expression of $I l 1 \beta$, Il6 and Ifn $\gamma$ was significantly increased and $T g f \beta$ expression was significantly decreased in OVA/Sal-L. rhamnosus mice compared to the OVA/Sal-PBS group. The mRNA expression of $I l 1 \beta$ and Il6 was significantly decreased in OVA/OVA-L. rhamnosus mice as compared to the OVA/Sal-L. rhamnosus group (Figure 4D).

\section{$B$. breve treatment results in a strong up-regulation of mRNA for Tbet and Foxp3 and relevant Th cytokines mRNA expression in the lungs of chronically asthmatic mice}

To further explore the effects of the different treatments on Th responses in the lung, the mRNA expression of Thspecific transcription factors was measured (Figure 5). The expression of Th1-(Tbet) and Treg-(Foxp3) transcription factors was significantly decreased in the OVA/OVA-PBS group as compared to the OVA/Sal-PBS group. No correlations were found between the expression of these transcription factors and relevant Th cytokines. The expression of Th2-(Gata3), and Th17-(Roryt) transcription factors remained unchanged (Figure 5A). However, Tbet and Foxp3 expression was significantly increased in OVA/OVA- $B$. breve mice as compared to the OVA/OVA-PBS group. 


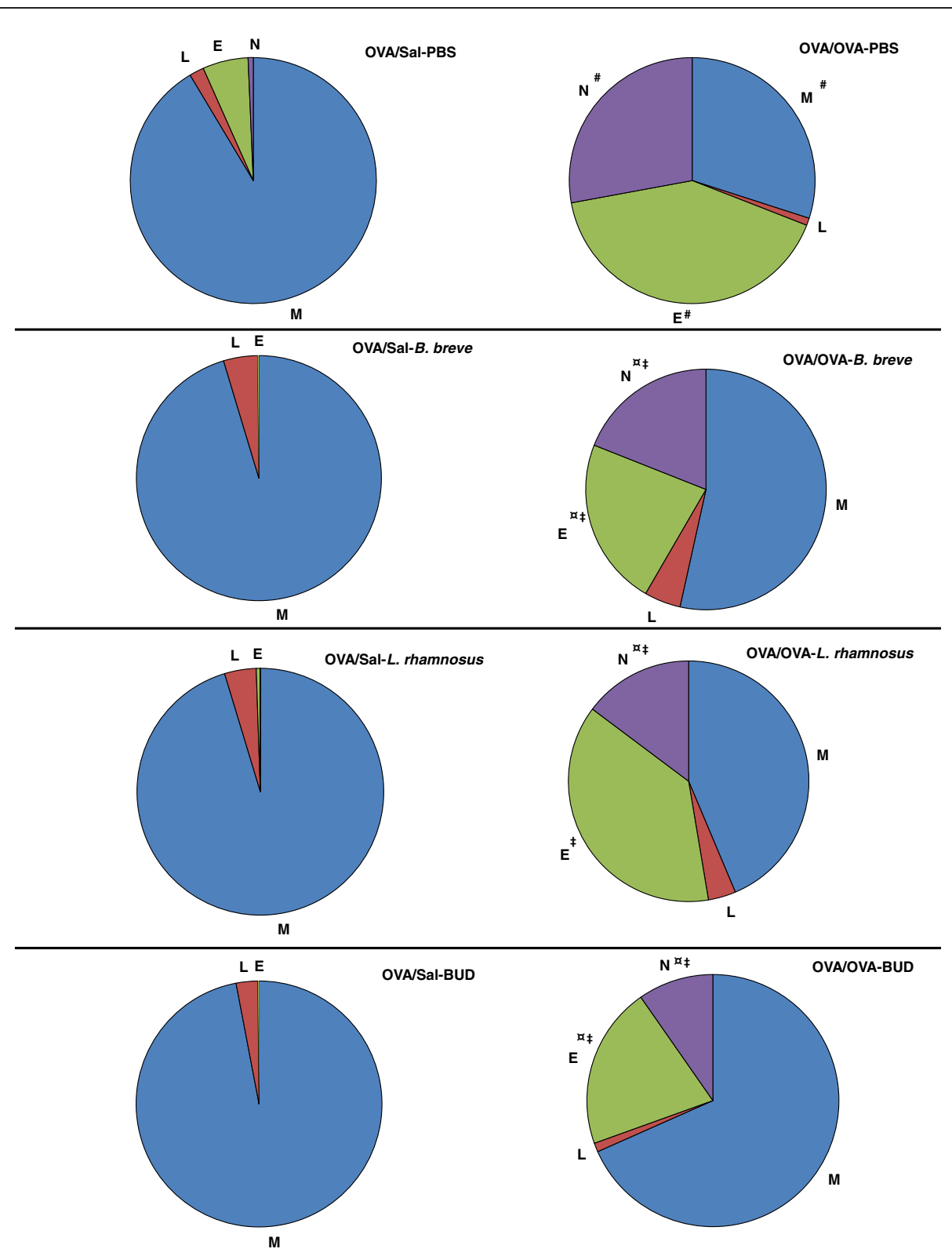

Figure 2 Beneficial bacteria and budesonide reduce the differential BAL fluid cell counts in chronic asthmatic mice. Pulmonary inflammation is represented by the influx of macrophages $(M)$, lymphocytes $(L)$, eosinophils $(E)$ and neutrophils $(N)$ in the BAL fluid. Differential cell counts are shown as percentages of the total cell count for each group. The charts show the mean, $n=6$ mice/group. Statistical significance of differences was tested using post hoc Bonferroni's multiple comparison test after one-way ANOVA. "Statistically significant difference $(p<0.05)$ compared to OVA/Sal-PBS mice. "Statistically significant difference $(p<0.05)$ compared to OVA/OVA-PBS mice. "Statistically significant difference $(p<0.05)$ compared to the OVA/Sal group in each treatment group. BUD $=$ budesonide.

Interestingly, expression of Tbet was tightly correlated with Ifny $\left(\mathrm{R}^{2}=0.903 ; \mathrm{p}=0.013\right)$ and Il12 $\left(\mathrm{R}^{2}=0.994 ; \mathrm{p}=0.003\right)$ and expression of Foxp3 was tightly correlated with $I l 10$ $\left(R^{2}=0.860 ; p=0.024\right)$ expression in whole lung tissue of OVA/OVA-B. breve mice. Compared to the OVA/Sal-PBS group, Foxp3 expression was almost two-fold increased $(\mathrm{P}>0.05)$ in the OVA/Sal-B. breve group. Expression of Tbet was significantly increased and expression of Gata3 was significantly decreased in OVA/OVA- $B$. breve mice as compared to the OVA/Sal-B. breve group (Figure 5B). A significant increase in the expression of Foxp3 was observed in the OVA/OVA-BUD group as compared to OVA/OVAPBS mice (Figure 5C). The expression of all Th-specific transcription factors remained unchanged in the OVA/ Sal- $L$. rhamnosus and OVA/OVA- $L$. rhamnosus groups (Figure 5D). Expression of Foxp3, however, was tightly 


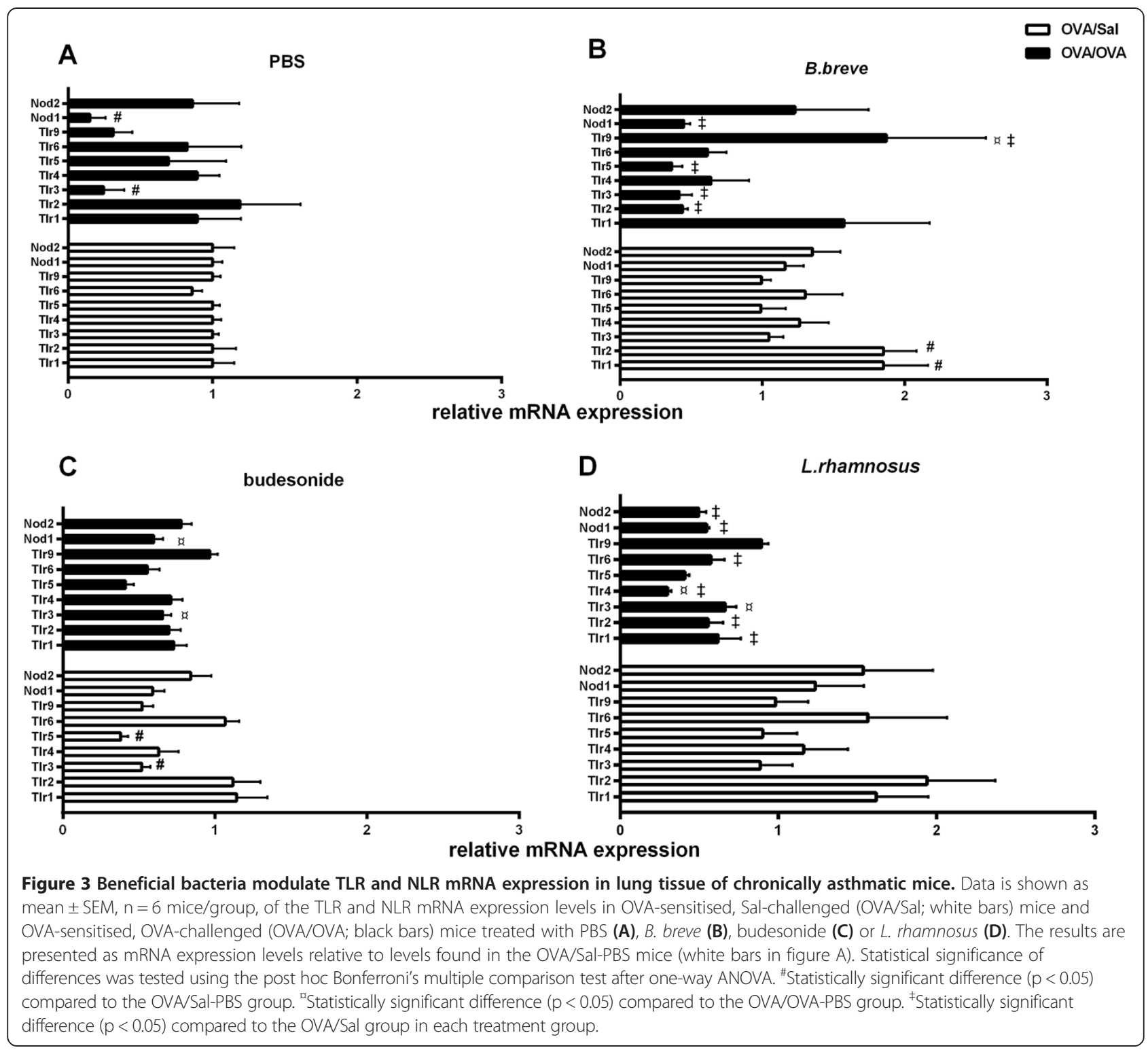

correlated with $I l 10$ expression $\left(\mathrm{R}^{2}=0.926 ; \mathrm{p}=0.009\right)$ in OVA/OVA-L. rhamnosus mice. None of the test groups showed correlations between the expression of Gata3 and Th2-related cytokines (Il4, Il5, Il13) and Roryt and Th17related cytokines (Il17, Il23).

B. breve skews the immune response away from Th2 and towards Treg in the lungs of chronically asthmatic mice To determine the extent of Th response skewing in the lung, ratios for Gata3/Tbet (Th2/Th1), Foxp3/ Roryt (Treg/Th17), Foxp3/Gata3 (Treg/Th2) and Foxp3/Tbet (Treg/Th1) mRNA expression were calculated (Table 2). The OVA/OVA-PBS groups showed a Th2-skewed immune response represented by a significant increase in Gata3/Tbet ratio as compared to OVA/Sal-PBS mice. This ratio was significantly decreased in the OVA/OVA-L. rhamnosus and OVA/ OVA- $B$. breve groups, but not the OVA/OVA-budesonide group. The Th2-reducing effect of OVA-OVA- $B$. breve was even more effective in challenged mice than healthy mice as the Gata3/Tbet ratio was decreased in OVA/OVA- $B$. breve mice as compared to the OVA/Sal- $B$. breve group. This was not the case for budesonide. Compared to the OVA/Sal-budesonide group, there was a significant increase in the Gata3/ Tbet ratio in the OVA/OVA-budesonide group. Interestingly, the Foxp3/Roryt and Foxp3/Gata3 ratios were significantly increased in OVA/OVA-B. breve mice as compared to the OVA/OVA-PBS group indicating an increase in Treg-associated responses. The ratio of Foxp3/Tbet did not differ significantly among the different treatment groups. 


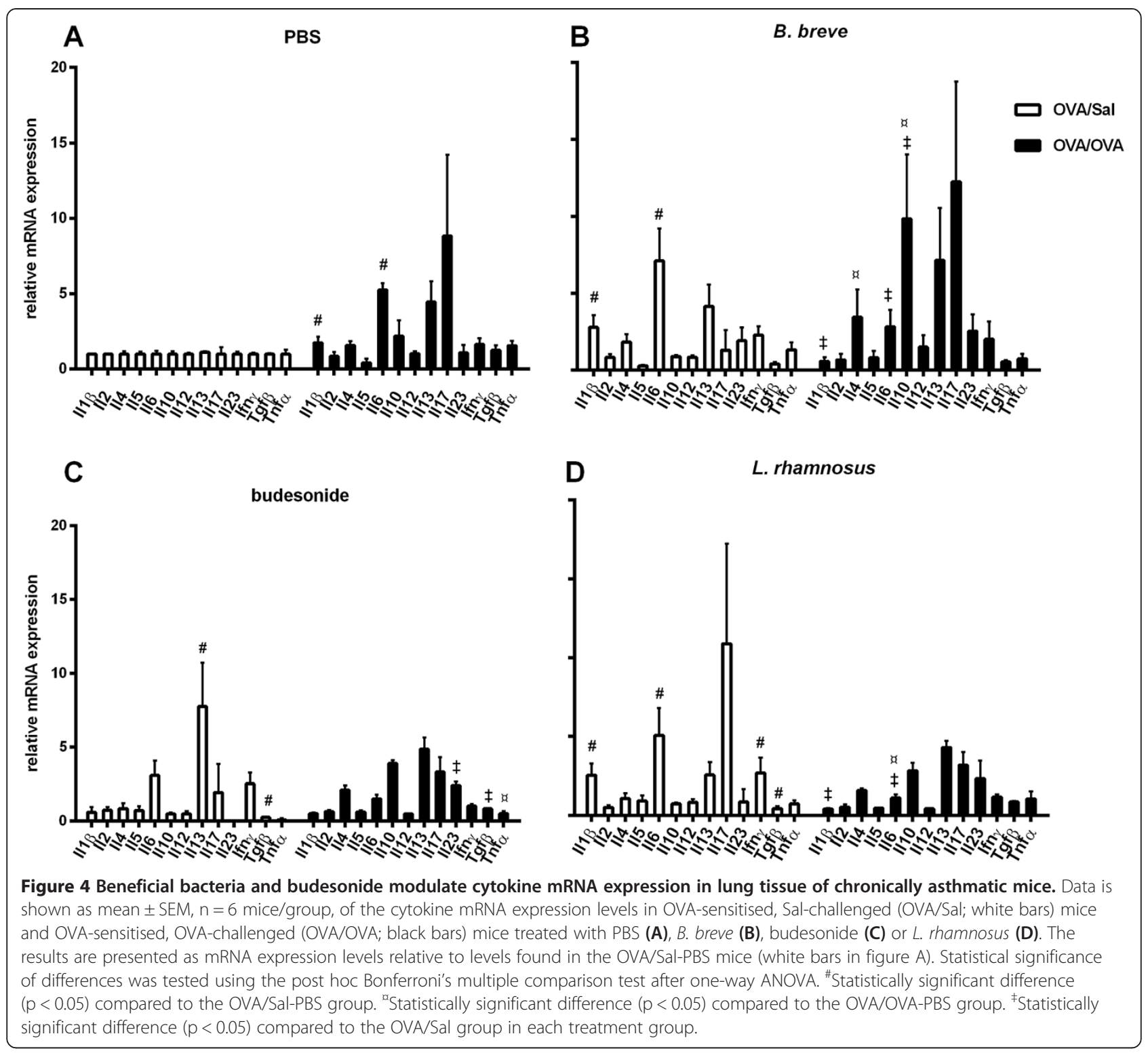

Beneficial bacteria and budesonide increase Foxp3 expression in blood Treg cells of chronically asthmatic mice

In order to determine if the transcriptional changes induced in Foxp3 expression could be found at a protein expression level, flow cytometry was employed to examine Foxp3 expression on Treg cells in the blood (Figure 6). Treg cells were identified as CD4+ Foxp3 + CD25hi T cells and the magnitude of Foxp3 expression on each cell was determined by examining the mean fluorescence intensity (MFI) of the Foxp3 staining. The percentage of CD4 cells that are Foxp3+ did not differ among the different groups (Figure 6A). The percentage of CD4 cells that are Foxp3+ and CD25hi was significantly decreased by all treatments as compared to both OVA/Sal-PBS and OVA/OVA-PBS groups (Figure 6B). However, all treatments increased the
Foxp3 expression in the blood Treg cells. The staining intensity of Foxp3 on day 56 was significantly higher in the OVA/OVA-B. breve, OVA/OVA-BUD and OVA/OVAL. rhamnosus groups as compared to OVA/OVA-PBS mice and to the OVA/Sal-PBS group (Figure $6 \mathrm{C}$ and D). The staining intensity of Foxp3 on day 0 (before sensitisation, challenge and treatment) did not differ among the different groups (data not shown).

\section{B. breve and $L$. rhamnosus are as effective as budesonide} in suppressing mucosal mast cell degranulation in chronically asthmatic mice

To examine the effect of the different treatments on mast cells activity, enzyme-linked immunosorbent assay was employed to measure $\mathrm{mMCP}-1$ protein levels in serum (Figure 7). The expression of $\mathrm{mMCP}-1$ was 

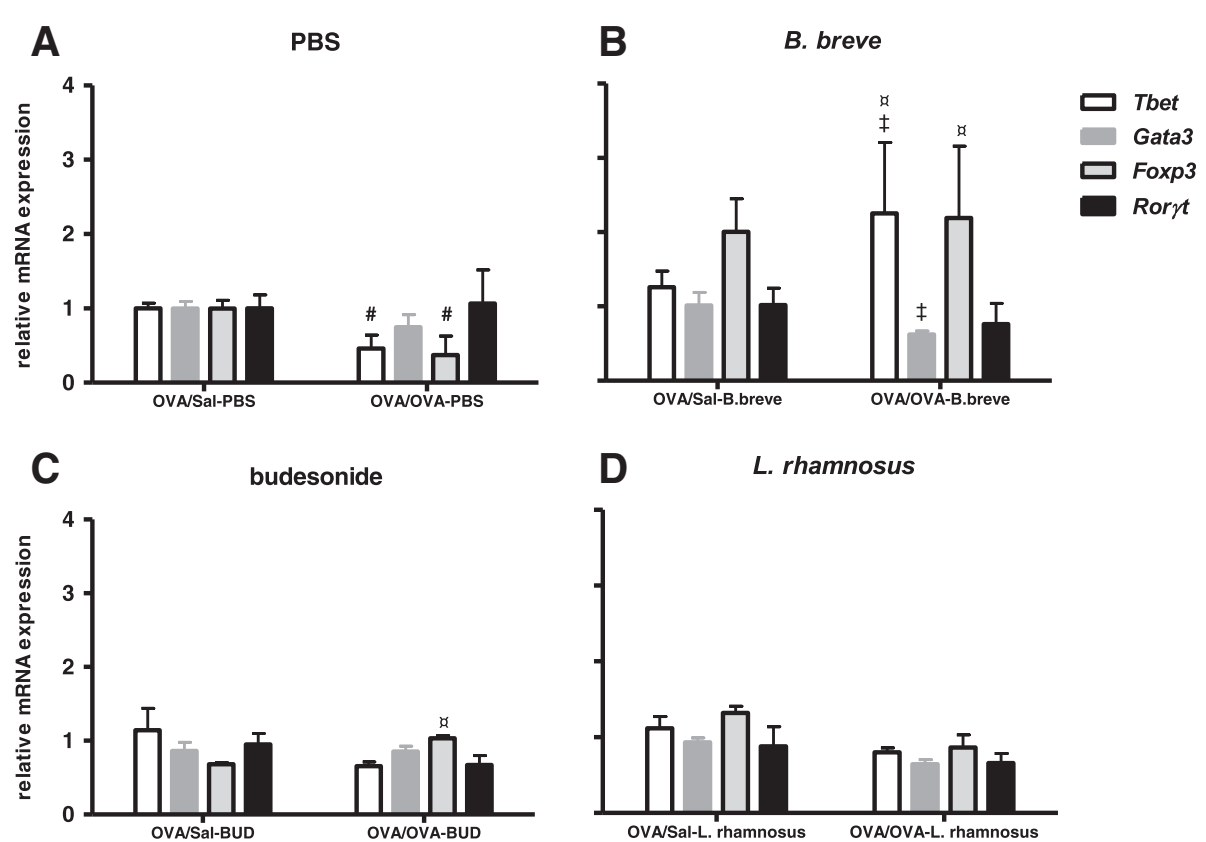

Figure 5 B. breve treatment up-regulates Tbet and Foxp3 mRNA expression in lungs of chronically asthmatic mice. Data is shown as mean $\pm S E M, n=6$ mice/group, of the transcription factor mRNA expression levels in OVA-sensitised, Sal-challenged (OVA/Sal) mice and OVA-sensitised, OVA-challenged (OVAVOVA) mice treated with PBS (A), B. breve (B), budesonide (C) or L. rhamnosus (D). The results are presented as mRNA expression levels relative to levels found in the OVAVSal-PBS mice (white bars in figure A). Statistical significance of differences was tested using the post hoc Bonferroni's multiple comparison test after one-way ANOVA. "Statistically significant difference $(p<0.05)$ compared to the OVAVSal-PBS group.

"Statistically significant difference $(p<0.05)$ compared to the OVAVOVA-PBS group. ${ }^{\ddagger}$ Statistically significant difference $(p<0.05)$ compared to the OVA/Sal group in each treatment group.

significantly increased in OVA/OVA-PBS mice as compared to the OVA/Sal-PBS group. All treatments were effective in suppressing mucosal mast cell degranulation in OVA/OVA mice, as depicted by decreased protein levels of mMCP-1 in serum when compared to the OVA/OVA-PBS group. mMCP-1 levels in control animals (OVA/Sal) did not change after administration of beneficial bacteria (data not shown).

\section{Beneficial bacteria and budesonide reduce $\mathrm{T}$ cell activity in chronically asthmatic mice}

To investigate the effect of the treatments on cytokine production by $\mathrm{T}$ cells in lung draining lymph nodes, TLNcell cultures were stimulated with anti-CD3, a pan $\mathrm{T}$ cell stimulator, and the cytokine levels in the supernatant were measured (Figure 8). Cytokine expression levels in medium-stimulated TLN cells did not differ among the different groups. The levels of IL-2, IL-4, IL-6, IL-17a, TNF- $\alpha$ and IFN- $\gamma$ were significantly increased in antiCD3-stimulated TLN cells of OVA/OVA-PBS mice as compared to samples from the OVA/Sal-PBS group. All treatments were effective in inhibiting $\mathrm{T}$ cell activity in OVA/OVA mice, significantly decreasing the levels of IL-2, IL-4, IL-6, IL-17a and TNF- $\alpha$ as compared to the OVA/OVA-PBS group. Additionally, L. rhamnosus and budesonide treatment significantly decreased the levels of
IFN- $\gamma$ in OVA/OVA mice as compared to the OVA/OVAPBS group. IL-10 levels were increased $(p>0.05)$ in the OVA/OVA-PBS and in all treatment groups as compared to the OVA/Sal-PBS group. No differences in cytokine expression were observed in the TLNs of the different control groups (data not shown).

\section{$B$. breve and $L$. rhamnosus are as effective as budesonide in suppressing airway remodelling features in chronically asthmatic mice}

In order to examine the effect of the different treatments on airway remodelling features, semi-quantivitive histological and immunhistochemical analyses of lung tissue were performed (Figure 9 and Table 3). In the lung sections of OVA/OVA-PBS mice, increased inflammation score and number of goblet cells, collagenous connective tissue fibers, airway smooth muscle cells and proliferating cells was observed as compared to the OVA/SalPBS group. All treatments were effective in reducing the inflammation score and decreasing the number of collagenous connective tissue fibers and proliferating cells in sensitised and challenged mice as compared to the OVA/OVA-PBS group. Yet, the number of airway smooth muscle cells remained unchanged in the different treatment groups. Budesonide treatment was also effective in reducing the number of goblet cells in the 
Table 2 B. breve skews the immune response away from Th2 and towards Treg in lungs of chronically asthmatic mice

\begin{tabular}{|c|c|c|c|c|c|}
\hline \multirow[t]{2}{*}{ Treatment } & \multirow[t]{2}{*}{ Ratio } & \multicolumn{2}{|l|}{ OVA/Sal } & \multicolumn{2}{|l|}{ OVA/OVA } \\
\hline & & Mean ratio & SEM & Mean ratio & SEM \\
\hline \multirow[t]{4}{*}{ PBS } & Gata3/Tbet & 1.03 & 0.10 & $1.66^{\#}$ & 0.37 \\
\hline & Foxp3/Roryt & 0.82 & 0.09 & 0.29 & 0.20 \\
\hline & Foxp3/Gata3 & 0.83 & 0.09 & 0.41 & 0.28 \\
\hline & Foxp3/Tbet & 0.86 & 0.09 & 0.69 & 0.47 \\
\hline \multirow[t]{4}{*}{ B. breve } & Gata3/Tbet & 0.83 & 0.14 & $0.29^{a, ~ \neq}$ & 0.02 \\
\hline & Foxp3/Ront & 1.62 & 0.36 & $2.36^{a}$ & 1.04 \\
\hline & Foxp3/Gata3 & 1.65 & 0.36 & $2.92^{\alpha}$ & 1.29 \\
\hline & Foxp3/Tbet & 1.36 & 0.30 & 0.83 & 0.37 \\
\hline \multirow[t]{4}{*}{ budesonide } & Gata3/Tbet & 0.78 & 0.10 & $1.34^{\ddagger}$ & 0.11 \\
\hline & Foxp3/Ront & 0.59 & 0.02 & 1.26 & 0.04 \\
\hline & Foxp3/Gata3 & 0.66 & 0.02 & 1.00 & 0.03 \\
\hline & Foxp3/Tbet & 0.51 & 0.02 & 1.35 & 0.04 \\
\hline \multirow[t]{4}{*}{ L. rhamnosus } & Gata3/Tbet & 0.86 & 0.06 & $0.83^{\alpha}$ & 0.08 \\
\hline & Foxp3/Roryt & 1.02 & 0.22 & 1.07 & 0.21 \\
\hline & Foxp3/Gata3 & 0.98 & 0.21 & 1.11 & 0.20 \\
\hline & Foxp3/Tbet & 0.84 & 0.18 & 0.92 & 0.18 \\
\hline
\end{tabular}

Ratios for Gata3/Tbet (Th2/Th1), Foxp3/Roryt (Treg/Th17), Foxp3/Gata3 (Treg/ Th2) and Foxp3/Tbet (Treg/Th1) mRNA expression in whole lung tissue are shown for OVA/Sal and OVA/OVA mice for each treatment. Data is represented as mean ratio $\pm S E M, n=6$ mice/group. The mean ratio was calculated by dividing the individual expression values for the first transcription factor (numerator) by the mean expression value for the second transcription factor (denominator). Statistical significance of differences was tested using post hoc Bonferroni's multiple comparison test after one-way ANOVA. "Statistically significant difference $(p<0.05)$ compared to the OVA/Sal-PBS group. " Statistically significant difference $(p<0.05)$ compared to the OVA/OVA-PBS group. " ${ }^{*}$ Statistically significant difference $(p<0.05)$ compared to OVA/Sal mice in each treatment group.

lung sections of OVA/OVA-BUD mice as compared to the OVA/OVA-PBS group.

\section{Discussion}

The aim of this study was to investigate the therapeutic effects of two different beneficial bacterial strains (B. breve M-16 V and L. rhamnosus NutRes1) and a reference treatment (budesonide) on features of the inflammatory response and airway remodelling in a murine model for chronic asthma. The lung resistance was significantly increased in OVA/OVA-PBS mice at all concentrations of methacholine as compared to the OVA/Sal-PBS group. Additionally, the total inflammatory cell number and individual BAL fluid cell counts, except lymphocytes, were significantly increased in OVA/OVA-PBS mice. Increased inflammation score and number of goblet cells, collagenous connective tissue fibers, airway smooth muscle cells and proliferating cells was observed in lung sections of these mice. Hence, our model mimics the airway inflammation and airway remodelling in chronic asthma
$[2,48,49]$. Treatment with $L$. rhamnosus or B. breve, hardly influenced the pathophysiological parameters in OVA/SalPBS animals. Interestingly, L. rhamnosus and budesonide treatments were effective in suppressing the lung resistance in OVA/OVA mice, significantly decreasing the AHR to methacholine as compared to the OVA/OVA-PBS group. B. breve treatment did not affect the AHR to methacholine. Airway inflammation is a characteristic feature of allergic asthma; however, the degree of airway inflammation is not always correlated with the degree of AHR [50]. In the present study, we demonstrate that L. rhamnosus prevents the ovalbumin-induced increase in basal airway resistance and AHR at lower concentrations of methacholine. In contrast to L. rhamnosus, B. breve was not able to significantly reduce changes in airway resistance. Although all the treatments were able to significantly reduce airway inflammation by $50 \%$, there was no complete reduction up till control levels as shown in the BAL fluid as well as in the histological evaluations. These remaining cells might be responsible for the AHR at higher concentrations of methacholine. There is no clear explanation why $L$. rhamnosus did suppress the increase in basal airway resistance and B. breve did not. Shifts in cell type such as the reduction in the relative number of macrophages or suppression of specific cytokines such as IFN- $\gamma$ might explain these observations. The above described results are in accordance with other studies in which beneficial bacteria and budesonide have been individually investigated [1,13,23,24,51-53]. Additionally, $B$. breve, $L$. rhamnosus and budesonide treatments reduced the inflammation score and decreased the number of collagenous connective tissue fibers and proliferating cells in ovalbumin-sensitised and challenged mice as compared to the OVA/OVA-PBS group. Budesonide treatment, but not $B$. breve or L. rhamnosus, was also effective in reducing the number of goblet cells in the lung sections of OVA/ OVA-budesonide mice. The number of airway smooth muscle cells remained unchanged in the different treatment groups as compared to OVA/OVA-mice.

To our knowledge, we demonstrate here for the first time that $L$. rhamnosus NutRes1 is as effective as budesonide in suppressing lung resistance in chronic allergic mice. Additionally, we demonstrate here that both beneficial bacterial strains are as effective as budesonide in reducing chronic allergic inflammation by attenuating the total inflammatory cell number as well as individual BAL fluid cell counts; and airway remodelling.

PRRs are key components of the innate immunity which are also involved in the activation and shaping of adaptive immunity. The function and expression of PRRs was linked to susceptibility towards allergic asthma. The mRNA expression of Tlr3 and Nod1 was significantly decreased in the lungs of OVA/OVA-PBS mice. Previous in vitro studies have demonstrated that upon activation 

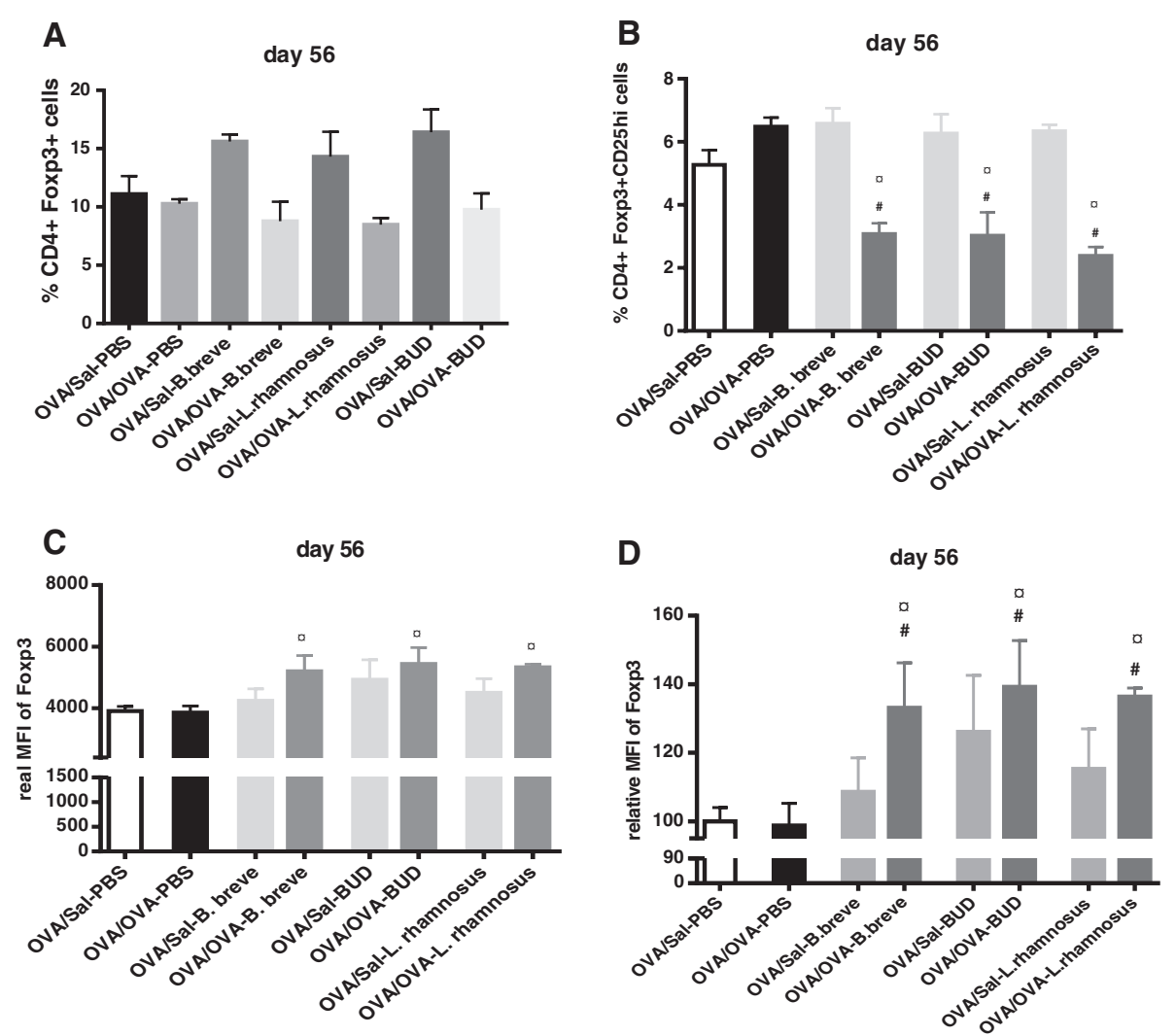

Figure 6 Beneficial bacteria and budesonide increase Foxp3 expression in blood Treg cells of chronically asthmatic mice. T cells were isolated on day 56 from mouse whole blood from OVA-sensitised, Sal-challenged (OVA/Sal) mice and OVA-sensitised, OVA-challenged (OVA/OVA) mice for each treatment. (A) Percentage of CD4 cells that are Foxp3+. (B) Percentage of CD4 cells that are Foxp3+ and CD25hi. (C) Real mean fluorescence intensity (MFI) of Foxp3 in Treg cells. (D) MFI levels relative to the OVA/Sal-PBS group (white bar). Data is shown as mean \pm SEM, $n=6$ mice/group. Statistical significance of differences was tested using the post hoc Bonferroni's multiple comparison test after one-way ANOVA. "Statistically significant difference $(p<0.05)$ compared to the OVA/Sal-PBS group. "Statistically significant difference $(p<0.05)$ compared to the OVA/OVA-PBS group. BUD = budesonide.

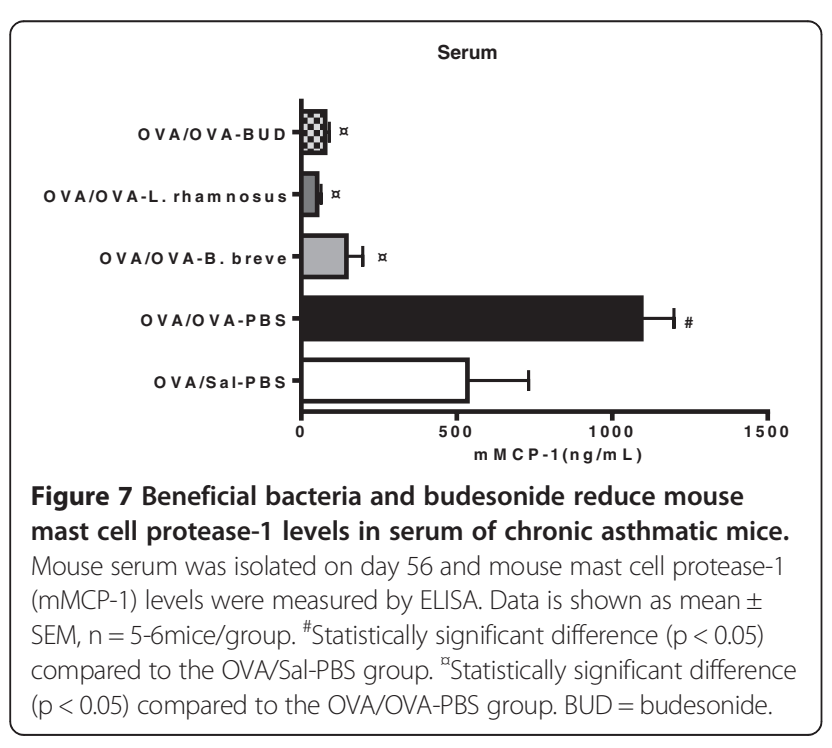

by its natural or endogenous ligands, Tlr3 induces upregulation of other TLRs, various cytokines and chemokines as well as its own expression and thereby contributes to exacerbation of inflammation [40]. Nod1 is an intracellular sensor of pathogenic bacteria. Single nucleotide polymorphisms in Nod1 gene were positively associated with susceptibility towards asthma in farming children and this PRR was reported to be necessary for neutrophil function in mice [25,33-35]. However, no direct associations between Tlr3 and Nod1 expression and function and asthma have been reported yet, and whether the decreased mRNA expression of Tlr3 and Nod 1 caused by the chronic inflammatory status of the animals is proinflammatory or anti-inflammatory is also unknown. Moreover, B. breve treatment significantly increased $\operatorname{Tl} 9$ expression. Since TLR9 was shown to exert its immunomodulatory effects on asthma by skewing the increased Th2/Th1 balance towards Th1, this may very well be the situation [37-39]. Budesonide treatment significantly increased the expression of Tlr3 and Nod1, restoring them 


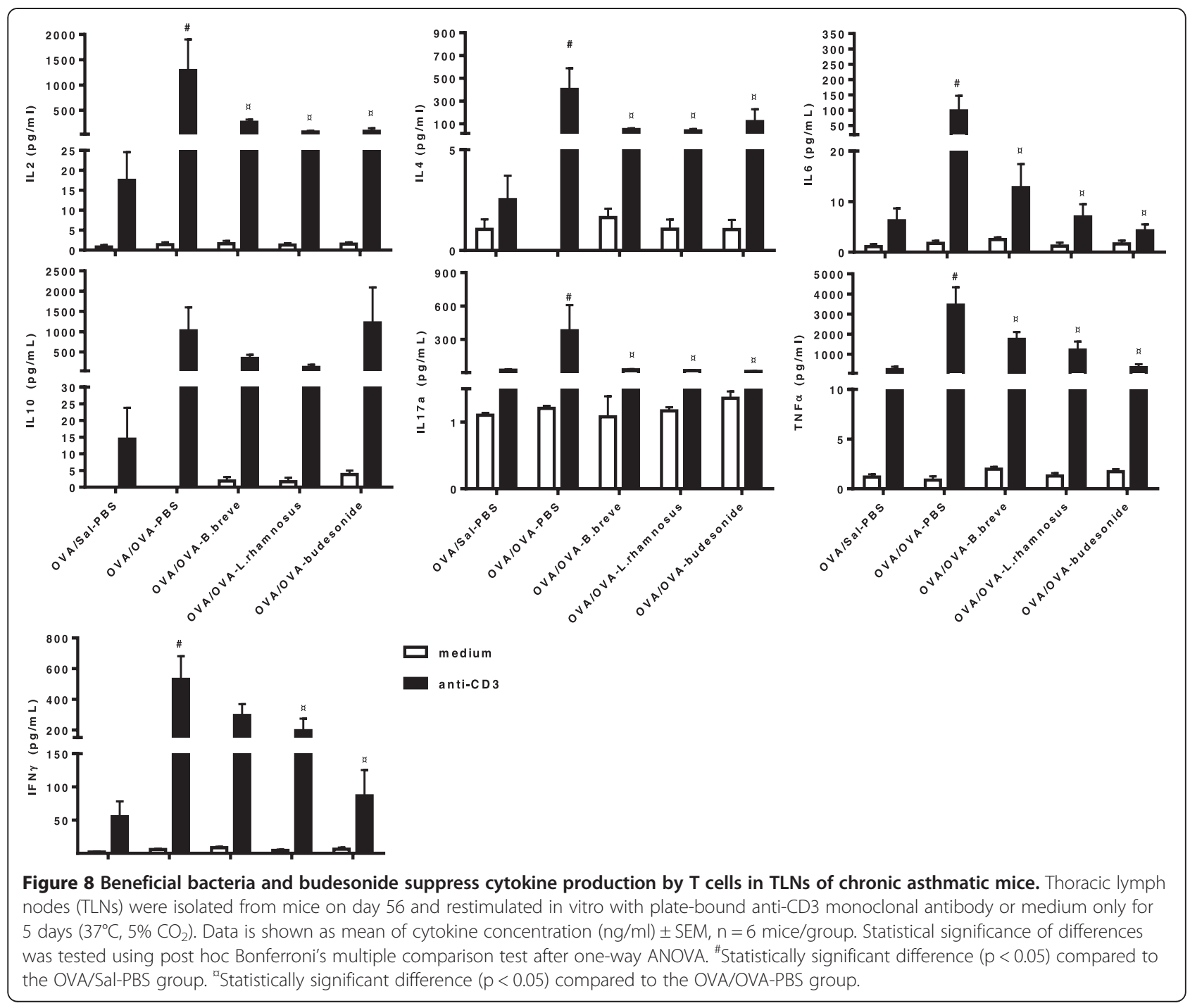

to normal levels, and raised $\operatorname{Tl} 9(\mathrm{P}>0.05)$ expression. This further supports a positive role for $\operatorname{Tl} 9$ and suggests that lowered Tlr3 and Nod1 measured in the asthmatic mice is pro-inflammatory in nature $[25,34,40]$. L. rhamnosus, besides significantly increasing Tlr3 expression and increasing the expression of Tlr9 expression $(P>0.05)$, significantly decreased the expression of $T l r 4$. Asthma patients have been shown to have low expression of TLR4 on their monocytes, lymphocytes and DCs suggesting that this reduction in TLR4 activation might contribute to the disease by reducing the release of Th1 and antiinflammatory cytokines [54]. These findings might suggest that L. rhamnosus treatment in asthmatic mice could not restore the expression of Tlr4 to its normal level. Taken together, we demonstrate here that the mRNA expression of PRRs in mouse lung tissue is differentially regulated by the different treatments. Yet, all treatments, especially B. breve, increased the expression of $T l r 9$.
Th2 cells play a key role in the pathogenesis of allergic asthma, and asthmatic patients were reported to have Th1/Th2 imbalances as well as disturbed Th17/Treg balances. Th2 dominance was observed in the OVA/ OVA-PBS group represented by a significant decrease in Th1 and Treg transcription factors and high Gata3/Tbet ratio. Hence, our model mimics the Th2-responses found in chronic asthma [1,2]. Importantly, $B$. breve shifted the immune balance towards Th1 and Treg, with significantly increased Foxp3/Roryt and Foxp3/Gata3 ratios and a significantly decreased Gata3/Tbet ratio. A different strain of Bifidobacterium, B. animalis, has been already shown to skew the Th1/Th2 balance towards Th1 in a preventative, acute mouse model for respiratory allergy [22]. Budesonide showed only a moderate effect and significantly increased the expression of Foxp3, but did not affect the Gata3/Tbet, Foxp3/Roryt, Foxp3/ Gata3 and Foxp3/Tbet ratios. These findings are 


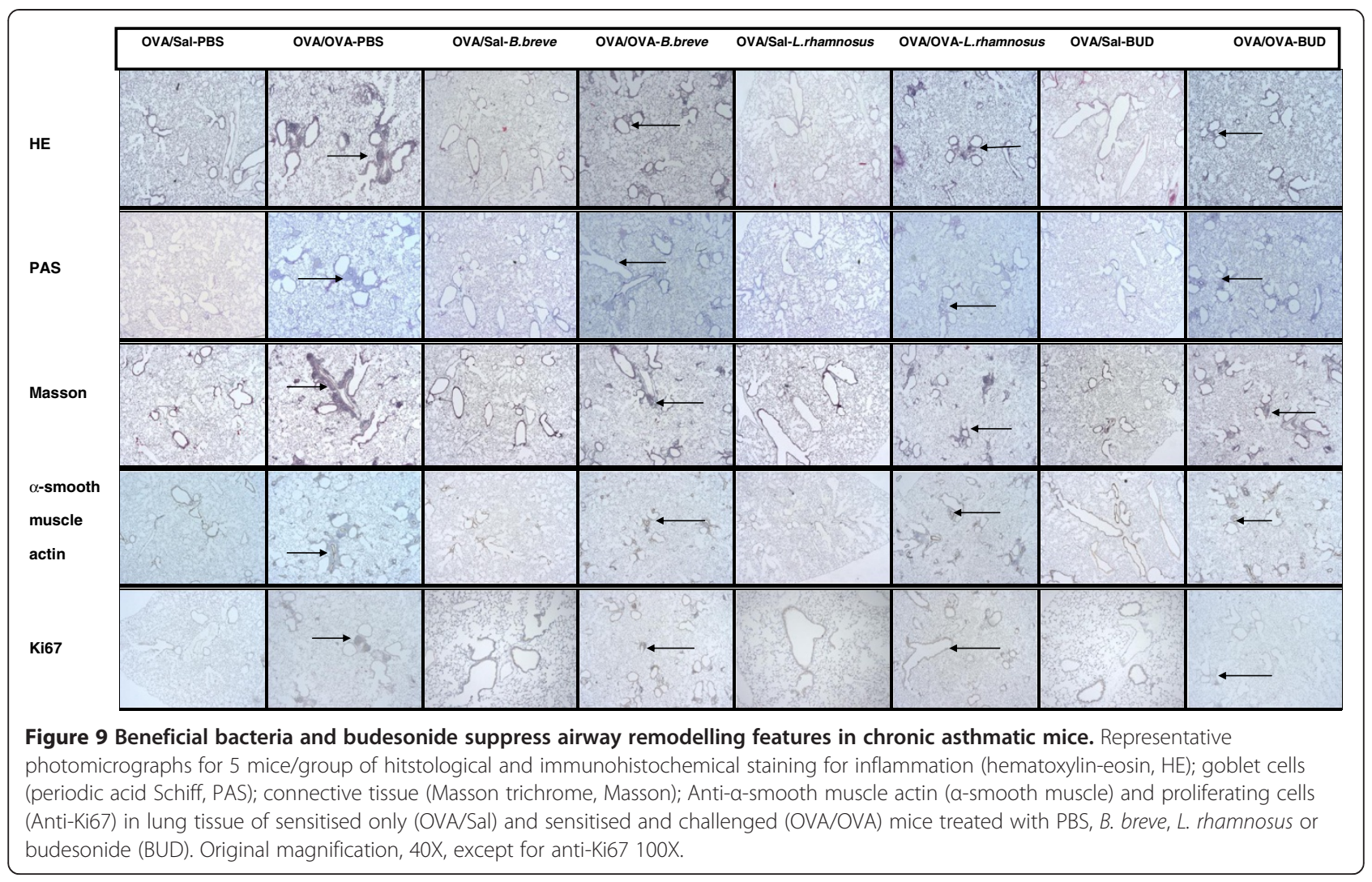

consistent with results of other studies which have shown that GCs treatment of asthmatic subjects encourages regulatory responses [55]. L. rhamnosus did not influence the mRNA expression of the different Thspecific transcription factors, but significantly decreased the Gata3/Tbet ratio. More importantly, the above observed effects of beneficial bacteria and budesonide on the Th responses in the lung are mirrored by the detection of high Foxp3-expressing Tregs in the blood of treated animals. Tregs play a key role in balancing immune responses and it was demonstrated that an increased expression of Foxp3 in Tregs is directly associated with increased function of these cells $[42,56]$. No significant differences in the percentage of $\mathrm{CD} 4+$ cells that are Foxp3+ were observed. A reduction in the populations of recently activated regulatory T $(\mathrm{CD} 4+$ Foxp $3+$ CD25hi) cells was observed in the treated mice. One possible reason for the loss of these cells may pertain to a reduction in inflammation caused by the treatments. Previous studies have demonstrated that Tregs can

Table 3 Overview of the hitstological and Immunohistochemical score

\begin{tabular}{llllll}
\hline Group & Inflammation (HE) & Goblet cells (PAS) & Connective tissue (Masson) & $\begin{array}{l}\text { a-smooth muscle cells } \\
\text { (anti-a-smooth muscle actin) }\end{array}$ & $\begin{array}{l}\text { Proliferating cells } \\
\text { (anti-Ki67) }\end{array}$ \\
\hline OVA/Sal-PBS & - & - & - & + & - \\
OVA/OVA-PBS & ++ & + & ++ & ++ & ++ \\
OVA/Sal-B. breve & - & - & + & + & $+/-$ \\
OVA/OVA-B. breve & + & + & + & + & + \\
OVA/Sal-L. rhamnosus & - & - & + & ++ & $+/-$ \\
OVA/OVA-L. rhamnosus & + & + & + & + & $+/-$ \\
OVA/Sal-budesonide & - & - & + & ++ & $+/-$ \\
OVA/OVA-budesonide & + & - & + & & +
\end{tabular}

Slides were reviewed in blinded fashion by two observers independently and slides were scored on the basis of the percentage of positive stained cells in the following way: - , no positive staining; + /-, less than $25 \%$ of cells stained positive;,+ 25 to $50 \%$ cells stained positive;,++ 50 to $75 \%$ cells stained positive. Results are presented as average score of 5 animals/group. 
become activated through inflammatory signals in the environment which functions as a natural feedback loop by preventing excessive inflammation. An example of this is through TLR2 stimulation [57].

Expression of the pro-inflammatory cytokines $I l 1 \beta$ and Il6 was significantly increased in the OVA/OVA-PBS group and expression of both Il13 and Il17 was also increased but not significantly. These four cytokines were reported to enhance asthma [30]. B. breve treatment, however, significantly increased the expression of the anti-inflammatory cytokine $I l 10$ and the Th2-associated cytokine Il4, yet, the mRNA expression of Gata3 was decreased. Interestingly, the expression of Thet was tightly correlated with Ifny and Il12, while Foxp3 expression was tightly correlated with $I l 10$ expression. It has been reported that $I L-12$ is involved in the differentiation of Th1 cells and that these cells suppress Th2 cells through the release of IFN- $\gamma$. Additionally, Tregs suppress other Th cell effector functions through the release of $I L-10$ [30]. Budesonide treatment significantly decreased the expression of the pro-inflammatory cytokine Tnfa which is in agreement with previously published studies demonstrating the anti-inflammatory effects of budesonide [58]. L. rhamnosus treatment significantly decreased the expression of $I l 6$, another highly pro-inflammatory cytokine. The mRNA expression of Foxp3 was tightly correlated with $I l 10$ expression.

Mast cells are key effector cells in allergic inflammation and mast cell degranulation is detected in asthmatic lungs. The expression of serum mMCP-1 was significantly increased in OVA/OVA-PBS mice as compared to the OVA/Sal-PBS group indicating pulmonary mast cell degranulation. Hence, previous studies demonstrated that mice undergoing a hypersensitivity reaction in the airways have high serum levels of mMCP-1 of pulmonary origin [59]. All treatments were effective in inhibiting mucosal mast cell degranulation, as shown by the significant decrease in the protein levels of mMCP-1 systemically, in serum, in treated mice as compared to the OVA/OVAPBS group. The mechanism by which these beneficial bacteria reduced mast cells degranulation still needs to be investigated; yet, these effects might be galectinesmediated. Recently, a combination of Bifidobacterium breve M-16 V with galacto- and fructo-oligosaccharides was shown to induce galectin-9 release from intestinal epithelial cells which in turn systemically suppressed allergic symptoms, including mast cells degranulation, in mice and humans. The same study demonstrated a negative correlation between increased serum galectin- 9 levels and serum mMCP-1 levels [60]. The mechanism by which budesonide affects mast cell degranulation still needs further investigation; yet, glucocorticoids were demonstrated to suppress mast cell activation in vitro through the upregulation of inhibitory regulators of these cells [61]. In addition to their effects on mast cells, B. breve, L. rhamnosus and budesonide were also effective at reducing cytokine production by T cells in the TLNs. The levels of IL-2, IL-4, IL-6, IL-17a, TNF- $\alpha$ and IFN- $\gamma$ were significantly increased in anti-CD3-stimulated TLN cells from OVA/ OVA-PBS mice as compared to the OVA/Sal-PBS group. IL-2, IL-4, IL-6, IL-17a and TNF- $\alpha$ were reported to be involved in asthma. Increased levels of IFN- $\gamma$ are found in individuals with severe asthma and acute exacerbation $[30,62]$. The levels of IL-2, IL-4, IL-6, IL-17a and TNF- $\alpha$ were significantly decreased in OVA/OVA mice treated with B. breve, L. rhamnosus or budesonide as compared to the OVA/OVA-PBS group. Levels of IFN- $\gamma$ were significantly decreased in OVA/OVA-L. rhamnosus and OVA/ OVA-budesonide mice. The level of IL-10 did not differ among the different groups, suggesting that the different treatments could not normalise IL-10 production in chronic allergic mice.

\section{Conclusions}

To our knowledge, this is the first report in which the therapeutic effects of long-term treatment with $B$. breve M-16 V, L. rhamnosus NutRes1 and budesonide on asthma are investigated in a murine ovalbumin-induced chronic allergic asthma model. In this current study we show that B. breve M-16 V and L. rhamnosus NutRes1 are as effective as budesonide in suppressing pulmonary airway inflammation, airway remodelling and inhibiting mast cell degranulation. Additionally, $L$. rhamnosus, but not $B$. breve, reduced lung resistance and IFN- $\gamma$ production by T cells in the TLNs indicating that treatment effects differ between the bacterial strains. mRNA expression of PRRs, T helper-specific cytokines and transcription factors are differentially modulated by the different treatments. Moreover, $B$. breve induced regulatory responses by increasing Il10 and Foxp 3 transcription in lung tissue and augmenting the mean fluorescence intensity of Foxp3 in blood $\mathrm{CD} 4+\mathrm{T}$ cells. These findings show that $B$. breve M-16 V and L. rhamnosus NutRes1 may be beneficial in the management of chronic allergic asthma in a therapeutic way.

\section{Additional files} Additional file 1: Table S1. Primers used for quantitative real-time PCR
analysis.
Additional file 2: Figure S1. Representative dot plots of T cells
analysis in the blood. T cells were isolated on day 56 from whole blood
of OVA-sensitised, Sal-challenged (OVA/Sal) mice and OVA-sensitised,
OVA-challenged (OVA/OVA) mice treated with PBS (I), B. breve (II),
L. rhamnosus (III) or budesonide (IV; BUD). T cells were gated based on
FSC-SSC pattern, followed by analysis of expression of CD4. Then
co-expression of Foxp3 and CD25 (regulatory T cells; Treg) was analyzed.
Data is representative for $n=6$ mice/group. 


\section{Competing interests}

Seil Sagar, Mary E Morgan, Si Chen, Johan Garssen, Gert Folkerts and Aletta D Kraneveld are employees of the Utrecht University and declare that they do not have a conflict of interest. Arjan P Vos, Jeroen van Bergenhenegouwen and Niki A Georgiou are employed by Danone Research as indicated in the author affiliations. This aside, there are no personal or financial conflicts of interest to report. Louis Boon is employed by Bioceros B.V. and has no personal financial conflicts of interest to report.

\section{Authors' contributions}

SS, designed and ran the chronic asthma mouse model, performed all in vivo and in vitro experiments, collected and analysed data, and wrote the manuscript. MEM, supervised the flow cytometry analysis and advised on data analysis. SC, carried out real-time-PCR analysis, and interpreted and analysed the data. APV and JB provided beneficial bacteria and gave technical support and conceptual advice. ADK, GF, NAG and JG, gave advice on model design, supervised the study and advised on data analysis. LB provided the anti-CD3 antibody. All authors discussed the results and implications and commented on the manuscript at all stages. All authors read and approved the final manuscript.

\section{Acknowledgments}

This study was performed within the framework of Dutch TI-Pharma (project number D1-101).

\section{Author details}

'Division of Pharmacology, Utrecht Institute for Pharmaceutical Sciences, Faculty of Science, Utrecht University, PO box 80082, 3508 TB Utrecht, The Netherlands. ${ }^{2}$ Danone Research, Centre for Specialised Nutrition, Wageningen, The Netherlands. ${ }^{3}$ Bioceros B.V., Utrecht, The Netherlands.

Received: 9 June 2013 Accepted: 3 April 2014

Published: 16 April 2014

\section{References}

1. Navarro S, Cossalter G, Chiavaroli C, Kanda A, Fleury S, Lazzari A, Cazareth J, Sparwasser T, Dombrowicz D, Glaichenhaus N, Julia V: The oral administration of bacterial extracts prevents asthma via the recruitment of regulatory T cells to the airways. Mucosal Immunol 2011, 4(1):53-65.

2. McMillan SJ, Lloyd CM: Prolonged allergen challenge in mice leads to persistent airway remodelling. Clin Exp Allergy 2004, 34(3):497-507.

3. Shifren A, Witt C, Christie C, Castro M: Mechanisms of remodeling in asthmatic airways. J Allergy (Cairo) 2012, 2012:316049. Article ID 316049, 12 pages.

4. Cho JY: Recent advances in mechanisms and treatments of airway remodeling in asthma: message from the bench side to the clinic. Korean J Intern Med 2011, 26(4):367-383.

5. Bai TR, Knight DA: Structural changes in the airways in asthma: observations and consequences. Clin Sci (Lond) 2005, 108(6):463-477.

6. Amin K, Janson C, Boman G, Venge P: The extracellular deposition of mast cell products is increased in hypertrophic airways smooth muscles in allergic asthma but not in nonallergic asthma. Allergy 2005, 60(10):1241-1247.

7. Brightling CE, Bradding P, Symon FA, Holgate ST, Wardlaw AJ, Pavord ID: Mast-cell infiltration of airway smooth muscle in asthma. N Engl J Med 2002, 346(22):1699-1705.

8. Romagnani S: Coming back to a missing immune deviation as the main explanatory mechanism for the hygiene hypothesis. J Allergy Clin Immunol 2007, 119(6):1511-1513.

9. Dimov W, Casale TB: Immunomodulators for asthma. Allergy Asthma Immunol Res 2010, 2(4):228-234.

10. Pejler G, Ronnberg E, Waern I, Wernersson S: Mast cell proteases: multifaceted regulators of inflammatory disease. Blood 2010, 115(24):4981-4990.

11. Sugimoto $K$, Kudo $M$, Sundaram $A$, Ren $X$, Huang $K$, Bernstein $X$, Wang $Y$, Raymond WW, Erle DJ, Abrink, Caughey GH, Huang X, Sheppard D: The alphavbeta6 integrin modulates airway hyperresponsiveness in mice by regulating intraepithelial mast cells. J Clin Invest 2012, 122(2):748-758.

12. Barnes PJ: Severe asthma: advances in current management and future therapy. J Allergy Clin Immunol 2012, 129(1):48-59.
13. Southam DS, Ellis R, Wattie J, Young S, Inman MD: Budesonide prevents but does not reverse sustained airway hyperresponsiveness in mice. Eur Respir J 2008, 32(4):970-978.

14. Abe A, Ohtomo T, Koyama S, Kitamura N, Kaminuma O, Mori A: Comparative analysis of steroid sensitivity of Thelper cells in vitro and in vivo. Int Arch Allergy Immunol 2011, 155(Suppl 1):110-116.

15. Noverr MC, Huffnagle GB: Does the microbiota regulate immune responses outside the gut? Trends Microbiol 2004, 12(12):562-568.

16. Kranich J, Maslowski KM, Mackay CR: Commensal flora and the regulation of inflammatory and autoimmune responses. Semin Immunol 2011, 23(2):139-145.

17. Georgiou NA, Garssen J, Witkamp RF: Pharma-nutrition interface: the gap is narrowing. Eur J Pharmacol 2011, 651(1-3):1-8

18. Vouloumanou EK, Makris GC, Karageorgopoulos DE, Falagas ME: Probiotics for the prevention of respiratory tract infections: a systematic review. Int J Antimicrob Agents 2009, 34(3):e191-e210.

19. Johannsen H, Prescott SL: Practical prebiotics, probiotics and synbiotics for allergists: how useful are they? Clin Exp Allergy 2009, 39(12):1801-1814.

20. Guarner F, Schaafsma GJ: Probiotics. Int J Food Microbiol 1998, 39(3):237-238.

21. Gourbeyre P, Denery S, Bodinier M: Probiotics, prebiotics, and synbiotics: impact on the gut immune system and allergic reactions. J Leukoc Biol 2011, 89(5):685-695.

22. Ezendam J, de Klerk A, Gremmer ER, van Loveren H: Effects of Bifidobacterium animalis administered during lactation on allergic and autoimmune responses in rodents. Clin Exp Immunol 2008, 154(3):424-431.

23. Hougee S, Vriesema AJ, Wijering SC, Knippels LM, Folkerts G, Nijkamp FP, Knol J, Garssen J: Oral treatment with probiotics reduces allergic symptoms in ovalbumin-sensitized mice: a bacterial strain comparative study. Int Arch Allergy Immunol 2010, 151(2):107-117.

24. Forsythe P, Inman MD, Bienenstock J: Oral treatment with live Lactobacillus reuteri inhibits the allergic airway response in mice. Am J Respir Crit Care Med 2007, 175(6):561-569.

25. Eder W, Klimecki W, Yu L, von Mutius E, Riedler J, Braun-Fahrlander C, Nowak D, Holst O, Martinez FD: Association between exposure to farming, allergies and genetic variation in CARD4/NOD1. Allergy 2006, 61(9):1117-1124

26. Nonaka Y, Izumo T, Izumi F, Maekawa T, Shibata H, Nakano A, Kishi A, Akatani K, Kiso Y: Antiallergic effects of Lactobacillus pentosus strain S-PT84 mediated by modulation of Th1/Th2 immunobalance and induction of IL-10 production. Int Arch Allergy Immunol 2008 145(3):249-257.

27. Kalliomaki M, Antoine JM, Herz U, Rijkers GT, Wells JM, Mercenier A: Guidance for substantiating the evidence for beneficial effects of probiotics: prevention and management of allergic diseases by probiotics. J Nutr 2010, 140(3):713S-721S.

28. Chen K, Xiang Y, Yao X, Liu Y, Gong W, Yoshimura T, Wang JM: The active contribution of Toll-like receptors to allergic airway inflammation. Int Immunopharmacol 2011, 11(10):1391-1398.

29. Uehara A, Fujimoto $Y$, Fukase $K$, Takada $H$ : Various human epithelial cells express functional Toll-like receptors, NOD1 and NOD2 to produce anti-microbial peptides, but not proinflammatory cytokines. Mol Immunol 2007, 44(12):3100-3111.

30. Barnes PJ: The cytokine network in chronic obstructive pulmonary disease. Am J Respir Cell Mol Biol 2009, 41(6):631-638.

31. Boyce JA, Bochner B, Finkelman FD, Rothenberg ME: Advances in mechanisms of asthma, allergy, and immunology in 2011. J Allergy Clin Immunol 2011, 129(2):335-341.

32. Heine H: TLRs, NLRs and RLRs: innate sensors and their impact on allergic diseases-a current view. Immunol Lett 2011, 139(1-2):14-24.

33. Eder W, Klimecki W, Yu L, von Mutius E, Riedler J, Braun-Fahrlander C, Nowak D, Martinez FD: Toll-like receptor 2 as a major gene for asthma in children of European farmers. J Allergy Clin Immunol 2004, 113(3):482-488.

34. Reijmerink NE, Bottema RW, Kerkhof M, Gerritsen J, Stelma FF, Thijs C, van Schayck CP, Smit HA, Brunekreef B, Koppelman GH, Postma DS: TLR-related pathway analysis: novel gene-gene interactions in the development of asthma and atopy. Allergy 2010, 65(2):199-207.

35. Clarke TB, Davis KM, Lysenko ES, Zhou AY, Yu Y, Weiser JN: Recognition of peptidoglycan from the microbiota by Nod1 enhances systemic innate immunity. Nat Med 2010, 16(2):228-231. 
36. Kabesch M, Peters W, Carr D, Leupold W, Weiland SK, von Mutius E: Association between polymorphisms in caspase recruitment domain containing protein 15 and allergy in two German populations. J Allergy Clin Immunol 2003, 111(4):813-817.

37. Reece P, Thanendran A, Crawford L, Tulic MK, Thabane L, Prescott SL, Sehmi R, Denburg JA: Maternal allergy modulates cord blood hematopoietic progenitor Toll-like receptor expression and function. J Allergy Clin Immunol 2011, 127(2):447-453.

38. Gupta GK, Agrawal DK: CpG oligodeoxynucleotides as TLR9 agonists: therapeutic application in allergy and asthma. BioDrugs 2010, 24(4):225-235.

39. Lachheb J, Dhifallah IB, Chelbi H, Hamzaoui K, Hamzaoui A: Toll-like receptors and CD14 genes polymorphisms and susceptibility to asthma in Tunisian children. Tissue Antigens 2008, 71(5):417-425.

40. Stowell NC, Seideman J, Raymond HA, Smalley KA, Lamb RJ, Egenolf DD, Bugelski PJ, Murray LA, Marsters PA, Bunting RA, Flavell RA, Alexopoulou L, San Mateo LR, Griswold DE, Sarisky RT, Mbow ML, Das AM: Long-term activation of TLR3 by poly(l:C) induces inflammation and impairs lung function in mice. Respir Res 2009, 10:43.

41. Mizel SB, Honko AN, Moors MA, Smith PS, West AP: Induction of macrophage nitric oxide production by Gram-negative flagellin involves signaling via heteromeric Toll-like receptor 5/Toll-like receptor 4 complexes. J Immunol 2003, 170(12):6217-6223.

42. Lloyd CM, Hawrylowicz CM: Regulatory T cells in asthma. Immunity 2009, 31(3):438-449.

43. Shi $Y H$, Shi GC, Wan HY, Jiang $L H, A i X Y$, Zhu HX, Tang $W$, Ma JY, Jin $X Y$, Zhang BY: Coexistence of Th1/Th2 and Th17/Treg imbalances in patients with allergic asthma. Chin Med J (Engl) 2011, 124(13):1951-1956.

44. Robinson DS: The role of the T cell in asthma. J Allergy Clin Immunol 2010, 126(6):1081-1091. quiz 1092-1083.

45. Provoost S, Maes T, van Durme YM, Gevaert P, Bachert C, Schmidt-Weber CB, Brusselle GG, Joos GF, Tournoy KG: Decreased FOXP3 protein expression in patients with asthma. Allergy 2009, 64(10):1539-1546.

46. Vale-Pereira S, Todo-Bom A, Geraldes L, Schmidt-Weber C, Akdis CA, Mota-Pinto A: FoxP3, GATA-3 and T-bet expression in elderly asthma. Clin Exp Allergy 2011, 41(4):490-496.

47. Braber S, Overbeek SA, Koelink PJ, Henricks PA, Zaman GJ, Garssen J, Kraneveld AD, Folkerts G: CXCR2 antagonists block the N-Ac-PGP-induced neutrophil influx in the airways of mice, but not the production of the chemokine CXCL1. Eur J Pharmacol 2011, 668(3):443-449.

48. Fernandez-Rodriguez S, Ford WR, Broadley KJ, Kidd EJ: Establishing the phenotype in novel acute and chronic murine models of allergic asthma. Int Immunopharmacol 2008, 8(5):756-763.

49. Nials AT, Uddin S: Mouse models of allergic asthma: acute and chronic allergen challenge. Dis Model Mech 2008, 1(4-5):213-220.

50. Janssen-Heininger YM, Irvin CG, Scheller EV, Brown AL, Kolls JK, Alcorn JF: Airway Hyperresponsiveness and Inflammation: causation, correlation, or no relation? J Allergy Ther 2012, 2012(Suppl 1):

51. Li CY, Lin HC, Hsueh KC, Wu SF, Fang SH: Oral administration of Lactobacillus salivarius inhibits the allergic airway response in mice. Can J Microbiol 2010, 56(5):373-379.

52. Yu J, Jang SO, Kim BJ, Song YH, Kwon JW, Kang MJ, Choi WA, Jung HD, Hong SJ: The effects of Lactobacillus rhamnosus on the prevention of asthma in a Murine model. Allergy Asthma Immunol Res 2010, 2(3):199-205.

53. Jang SO, Kim HJ, Kim YJ, Kang MJ, Kwon JW, Seo JH, Kim HY, Kim BJ, Yu J, Hong SJ: Asthma prevention by Lactobacillus Rhamnosus in a mouse model is associated with CD4(+)CD25(+)Foxp3(+) T Cells. Allergy Asthma Immunol Res 2012, 4(3):150-156.

54. Lun SW, Wong CK, Ko FW, Hui DS, Lam CW: Expression and functional analysis of toll-like receptors of peripheral blood cells in asthmatic patients: implication for immunopathological mechanism in asthma. J Clin Immunol 2009, 29(3):330-342.

55. Karagiannidis C, Akdis M, Holopainen P, Woolley NJ, Hense G, Ruckert B, Mantel PY, Menz G, Akdis CA, Blaser K, Schmidt-Weber CB: Glucocorticoids upregulate FOXP3 expression and regulatory T cells in asthma. J Allergy Clin Immunol 2004, 114(6):1425-1433.

56. Chauhan SK, Saban DR, Lee HK, Dana R: Levels of Foxp3 in regulatory $T$ cells reflect their functional status in transplantation. J Immunol 2009, 182(1):148-153.

57. Sutmuller RP, den Brok MH, Kramer M, Bennink EJ, Toonen LW, Kullberg BJ, Joosten LA, Akira S, Netea MG, Adema GJ: Toll-like receptor 2 controls expansion and function of regulatory T cells. J Clin Invest 2006, 116(2):485-494.

58. Montuschi P, Barnes PJ: New perspectives in pharmacological treatment of mild persistent asthma. Drug Discov Today 2011, 16(23-24):1084-1091.

59. Kraneveld AD, van der Kleij HP, Kool M, van Houwelingen AH, Weitenberg AC, Redegeld FA, Nijkamp FP: Key role for mast cells in nonatopic asthma. $\mathrm{J}$ Immunol 2002, 169(4):2044-2053.

60. de Kivit S, Saeland E, Kraneveld AD, van de Kant HJ, Schouten B, van Esch BC, Knol J, Sprikkelman AB, van der Aa LB, Knippels LM, Garssen J, van Kooyk Y, Willemsen LE: Galectin-9 induced by dietary synbiotics is involved in suppression of allergic symptoms in mice and humans. Allergy 2012, 67(3):343-352.

61. Park SK, Beaven MA: Mechanism of upregulation of the inhibitory regulator, src-like adaptor protein (SLAP), by glucocorticoids in mast cells. Mol Immunol 2009, 46(3):492-497.

62. Kumar RK, Webb DC, Herbert C, Foster PS: Interferon-gamma as a possible target in chronic asthma. Inflamm Allergy Drug Targets 2006, 5(4):253-256.

doi:10.1186/1465-9921-15-46

Cite this article as: Sagar et al.: Bifidobacterium breve and Lactobacillus rhamnosus treatment is as effective as budesonide at reducing inflammation in a murine model for chronic asthma. Respiratory Research 2014 15:46

\section{Submit your next manuscript to BioMed Central and take full advantage of:}

- Convenient online submission

- Thorough peer review

- No space constraints or color figure charges

- Immediate publication on acceptance

- Inclusion in PubMed, CAS, Scopus and Google Scholar

- Research which is freely available for redistribution 